\title{
LA PENALIZACIÓN DE LA INCITACIÓN AL ODIO A LA LUZ DE LA JURISPRUDENCIA COMPARADA
}

\author{
THE CRIMINALIZATION OF HATE SPEECH IN CHILE IN LIGHT OF \\ COMPARATIVE CASE LAW
}

\begin{abstract}
Álvaro Paúl Díaz
RESUMEN: Este artículo analiza cuáles son las posiciones que existen en el Derecho comparado en materia de penalización de la incitación al odio. Junto a ello, hace referencia a la normativa vigente en Chile, a una sentencia que la aplicó, y al proyecto de ley que busca establecer un nuevo tipo penal de incitación al odio. Además, el autor revisa algunos argumentos a favor y en contra de la proscripción de la incitación al odio, refiriéndose especialmente a jurisprudencia extranjera. Por último, y cimentado en las consideraciones previas, propone requisitos con los que debería contar una norma que prohíba el hate speech.

Palabras clave: Incitación al Odio, Libertad de Expresión, Derecho Comparado, Derechos Humanos, Regulación.

ABSTRACT: This article analyzes different positions in comparative law about the criminalization of hate speech in Chile. As well as that, it refers to the currently applicable Chilean law, to a case decision which applied it, and to the bill which is seeking to establish a new hate speech crime. The author considers also some arguments in favour and against banning hate speech, taking non-Chilean case law into especial consideration. Building on the forgoing, this article proposes some requirements which should be complied with by a hate speech law.
\end{abstract}

Key words: Hate Speech, Freedom of Expression, Comparative Law, Human Rights, Regulation.

\section{INTRODUCCIÓN}

No es infrecuente leer o escuchar hablar de la "lucha de clases" como ideario político que algunos consideran aún vigente. La sociedad parece estar acostumbrada a este discurso y por ello no se escandaliza. Sin embargo, sería difícil sostener que este llamado a la violencia no es una forma de incitación al odio o hate speech. Algo similar se puede afirmar respecto a la polémica frase "Pitéate un flaite", utilizada hace un tiempo como consigna

\footnotetext{
* Licenciado en Ciencias Jurídicas, U. de los Andes; Máster en Derecho, U. de Oxford. Estudiante de Máster de Investigación en Trinity College Dublin. Correo electrónico: a.pauldiaz@stcatz.oxon.org. Los párrafos o frases originalmente en inglés fueron traducidos libremente por el autor. Las sentencias húngaras fueron tomadas de la versión inglesa disponible en http://www.mkab.hu/index.php?id=decisions. Agradezco los comentarios de José Francisco García, José Manuel Díaz de Valdés, Adolfo Paúl y Fernando Tolentino.
} 
"humorística" de un programa radial ${ }^{1}$. ¿Corresponderá perseguir criminalmente a quienes profieren tales expresiones? La respuesta a esta pregunta dependerá en gran medida de la posición que se adopte ante la libertad de expresión, un derecho fundamental en toda democracia.

La importancia de la libertad de expresión es algo indiscutido. Incluso, se ha dicho que este derecho tiene una posición preferencial en los catálogos de garantías constitucionales $^{2}$. Sin embargo, no existe un consenso sobre el motivo de esta particular relevancia. Algunos alegan que su calidad de derecho fundamental deriva de la misma dignidad humana, otros, con una mirada más utilitarista, postulan que su importancia se sigue de los bienes que ella trae consigo, como el que solo a través de debates basados en la libertad de expresión es posible alcanzar la verdad, o que es un requisito necesario para la democracia ${ }^{3}$. Quienes sostienen estas posiciones divergentes coinciden en que la libertad de expresión es un derecho limitado, pues hay variados motivos que así lo justifican; como mantener el orden público, resguardar la dignidad humana y el respeto a la honra.

Incluso la jurisprudencia de Estados Unidos, quizá una de las que asigna un mayor valor a la libertad de expresión, declaró en el caso Chaplinsky vs. New Hampshire (1942) que el derecho constitucional a la libertad de expresión (free speech) no es absoluto ${ }^{4}$. Tal fallo sostuvo que existen expresiones cuya restricción y castigo no generan problemas constitucionales, como "la lasciva y obscena, la profana, la injuriosa y la insultante, o las palabras 'pendencieras' (fighting words) -las que, por solo ser proferidas, infligen daño o tienden a incitar a un inmediato quiebre de la paz-" portancia teórica, en la práctica ha dejado de sentar un precedente tan restrictivo ${ }^{6}$.

El presente estudio se referirá a una forma particular de restricción a la libertad de expresión: la prohibición de la incitación al odio. En este análisis se observarán los diversos enfoques adoptados frente al hate speech, y cuáles son los requisitos que debieran cumplirse para que su proscripción sea adecuada. Para ello, la primera sección expondrá

\footnotetext{
${ }^{1}$ Diario El Mercurio, Vida y Salud, 18 de noviembre de 2005. El concepto flaite es un vulgarismo ambiguo, referido generalmente a personas de baja condición social que comparten ciertas características conductuales. Tiene alguna relación con el término roto, usado para designar a una "persona mal educada, de modales groseros" (Diccionario de la R.A.E.), aunque una de las acepciones de flaite tiene una connotación delictual. El vulgarismo pitear puede entenderse de diversos modos, pero, aplicado a personas, podría significar matar.

2 Nogueira Alcalá (2000) p. 348.

3 Para un detallado estudio sobre los principios que justifican la libertad de expresión y sus límites, ver FAúNDeZ Ledesma (2004) pp. 33 ss.

${ }^{4}$ Pp. 571 y 572. La libertad de expresión es reconocida en la primera enmienda a la Constitución de los EE.UU. en los siguientes términos: "El Congreso no (...) impondrá obstáculos a la libertad de expresión o de la prensa”. Constitución de los Estados Unidos de América (1788).

5 Chaplinsky vs. New Hampshire (1942) pp. 571 y 572. Este criterio no solo limita la libertad de expresión -consagrada como un absoluto en la Primera Enmienda-, sino que parece redefinirla como el derecho a emitir expresiones que no sean ofensivas ni inmorales.

${ }^{6}$ En efecto, los conceptos que este fallo enumera como restricciones a la libertad de expresión han sido estrictamente delimitados por la jurisprudencia estadounidense. Así, por ejemplo, las expresiones deben cruzar umbrales o estándares muy altos para ser consideradas obscenas o fighting words. Ver Miller vs. California (1973) y Brandenburg vs. Ohio (1969), respectivamente. En relación al segundo punto ver también Nota (1993): “The Demise...".
} 
algunas cuestiones generales sobre la regulación de la incitación al odio, comenzando por una breve descripción de qué se entiende por prohibición del hate speech, siguiendo con una revisión de los dos enfoques que, a grandes rasgos, pueden adoptarse frente a este tema, y culminando con un análisis de la situación chilena en la materia. Una segunda parte de este trabajo, después de enunciar los efectos negativos de la incitación al odio, esquematizará los pros y contras de su penalización. Por último, la tercera sección de este estudio enumerará cuáles son, en caso de optarse por proscribir el hate speech, las características que debiera tener una norma que lo haga. Para hacer todo lo anterior, este artículo analizará cierta jurisprudencia comparada.

\section{NOCIONES GENERALES SOBRE LA REGULACIÓN DE LA INCITACIÓN AL ODIO}

\subsection{Cuestión previa}

La intención de este trabajo no es encontrar una definición del hate speech ni embarcarse en un análisis detallado de sus características. Sin embargo, es imposible evitar señalar qué se entiende por proscripción de la incitación al odio. Basados en ciertos tratados internacionales ratificados por $\mathrm{Chile}^{7}$, podría decirse que la prohibición del hate speech es una limitación a la libertad de expresión, más o menos estricta, destinada a prohibir locuciones $\mathrm{u}$ otras expresiones que inciten a la discriminación, hostilidad o violencia en contra de una o más personas en virtud de su pertenencia un grupo determinado, sea este una nación, raza, religión o algún otro, o en contra del grupo mismo. Debe notarse que el hate speech "va más allá de la simple expresión de rechazo o antipatía", ya que "trata de promover la hostilidad contra las personas respecto de quienes se dirige la conducta discriminatoria"'.

Las sanciones que se apliquen a los actos de incitación al odio prohibidos por la ley pueden ser de carácter civil, infraccional o penal, habiendo ordenamientos jurídicos donde coexisten dos o más tipos de normas regulatorias del hate speech ${ }^{10}$. Este artículo no se referirá a las normativas civiles en materia de incitación al odio, sin perjuicio de que muchas de las afirmaciones de este trabajo les son igualmente aplicables especialmente cuando las indemnizaciones ordenadas parecen tener una finalidad sancionatoria en vez de compensatoria-, y de que uno de los casos que se mencionarán dice relación con una sentencia previa en que se declaró la responsabilidad civil del emisor del hate speech.

Existen principalmente dos modos de entender la incitación al odio y su relación con la garantía constitucional de la libertad de expresión. El primero afirma que el hate speech es una forma de discurso, por lo que goza de la protección a la libertad de expre-

\footnotetext{
7 Art. 20 Inc. 2 del Pacto Internacional de Derechos Civiles y Políticos, y Art. 13 párr. $5^{\circ}$ de la Convención Americana sobre DD.HH. Ver también el Art. 4 de la Convención Internacional sobre la Eliminación de todas las Formas de Discriminación Racial.

8 Politoff (1999) p. 199.

${ }^{9}$ Politoff (1999) p. 199.

${ }^{10}$ V. gr. En Canadá coexisten las secciones 319 del Criminal Code C-46 (2010) y 13 de la Canadian Human Rights Act (2009).
} 
sión, sin perjuicio de que puede ser limitado en casos muy graves, principalmente, en pos del mantenimiento del bien común. Un segundo modo considera, en general, que la incitación al odio no constituye una forma de expresión protegida por la garantía constitucional de la libertad de expresión. Estas dos posiciones, que se describirán a continuación, no se refieren a posturas sobre la bondad o malicia de la incitación al odio, ya que los exponentes de ambos enfoques pueden estar de acuerdo en la negatividad de las expresiones de hate speech. La distinción entre estas posiciones se refiere a la actitud que le cabe al Estado en la regulación de la incitación al odio, y a la conveniencia de la penalización de este tipo de discurso.

\subsection{ENFOQUE LIBERAL}

La palabra liberal es un concepto que puede entenderse en diversos sentidos, algunos de ellos opuestos. Por ello, conviene aclarar que en este análisis se utilizará la expresión liberal en el sentido de "partidario de la libertad individual y social"11. Así, se llamará enfoque liberal a aquel que da una gran importancia a la libertad de expresión, motivo por el que tiene mayor tolerancia frente al hate speech. Esta postura se fundamenta en diversas teorías, como la del libre mercado de las ideas, la de la válvula de escape, la del valor inherente de la libre discusión de ideas o la del auxilio al proceso político ${ }^{12}$. La explicación de cada una de estas teorías podría distraer al lector del objeto principal de este trabajo, que no es revisar en detalle el enfoque liberal. Por ello, se expondrá a modo ejemplar solo una teoría, la del "libre mercado de las ideas". Ella sostiene que una sociedad que permita el intercambio libre de ideas proporciona el mejor ambiente para el surgimiento de la ver$\operatorname{dad}^{13}$, mientras que una sociedad en la que solo pueden proferirse verdades oficiales será menos propicia para los descubrimientos científicos o filosóficos y, en definitiva, para la libertad. Esta fuerte protección de la expresión tendrá, como efecto indeseado, que en el "libre mercado de las ideas" se expondrán ideas erróneas o perjudiciales. Sin embargo, este enfoque considera que, tarde o temprano, las ideas verdaderas serán las que prevalecerán en esta libre competencia ${ }^{14}$.

Lo anterior no significa que el enfoque liberal se oponga a toda limitación de la expresión, pero sí, que exigirá demostrar los efectos gravemente dañosos de un discurso para poder restringirlo, y que pondrá la carga de la prueba en quien quiera limitarlo. Así, la protección de otros bienes, como la honra o el mantenimiento de la paz social, puede justificar la limitación de la libertad de expresión, pero el mal que produzcan estos discur-

\footnotetext{
${ }^{11}$ Una de las acepciones de la palabra liberal en el Diccionario de la R.A.E. es: "Partidario de la libertad individual y social en lo político y de la iniciativa privada en lo económico”.

12 Para un análisis sobre el modo en que estos argumentos justificarían la protección del hate speech, ver $\mathrm{RE}_{\mathrm{E}}$ DISH (1982) pp. 1161 ss.

13 Faúndez Ledesma (2004) pp. 51 ss. Algunos casos de hate speech en que se cita este argumento son: R.A.V. vs. City of St. Paul, Minnesota (1992) pp. 387, 401, 436, y en las opiniones disidentes de Canadá (Human Rights Commission) vs. Taylor (1990) p. 64 y R. vs. Keegstra (1990) pp. 110 y 111. Los números de página usados al citar jurisprudencia canadiense son aquellos obtenidos a partir del documento (en formato PDF) disponible en el sitio web de la Corte Suprema respectiva (http://scc.lexum.umontreal.ca/en/index.html).

${ }_{14}$ Una crítica sobre esta justificación puede verse en Redish (1982) pp. 1161 y 1162.
} 
sos debe estar probado y ser suficientemente grave ${ }^{15}$. Mientras no se pruebe una malicia suficiente como para sobrepasar el alto umbral de tolerancia del enfoque liberal frente a la expresión, el discurso estará protegido con independencia de su contenido ${ }^{16}$.

En la actualidad, uno de los mejores exponentes del enfoque liberal es Estados Uni$\operatorname{dos}^{17}$, motivo por el que se utilizarán casos de dicho país para ejemplificarlo. No obstante ello, no es adecuado identificar el enfoque liberal con la postura estadounidense, y el enfoque contrario con Europa, como hacen algunos. En efecto, sin perjuicio de lo dispuesto por la decisión marco de la Unión Europea en esta materia ${ }^{18}$, no todos los integrantes de Europa tienen un enfoque restrictivo ante la incitación al odio ${ }^{19}$. Por otro lado, la postura de Estados Unidos ha variado en el tiempo.

La postura de los Estados Unidos ha variado en el tiempo. Uno de los casos estadounidenses más relevantes en materia de incitación al odio es Beauharnais vs. People of the State of Illinois (1952). En este se mantuvo una multa cursada al dirigente de una liga de hombres blancos que, mientras buscaba apoyo en las calles para proponer la dictación de leyes de segregación, entregó panfletos que acusaban a la población negra de violaciones, robos y uso de drogas. Tal acción infringió el Código Penal de Illinois, que prohibía retratar a alguna clase de ciudadanos de cualquier raza, color, credo o religión, en forma "depravada, criminal, contraria a la castidad o carente de virtud", exponiéndolos a desprecio, burla o injurias, o produciendo el quebrantamiento de la paz o disturbios. El referido dirigente recurrió en contra de tal norma por violar la libertad de expresión (liberty of speech) y de prensa, y por establecer un tipo penal en forma muy vaga.

La mayoría de la Corte Suprema de Estados Unidos consideró que la norma impugnada no era imprecisa, y que su lenguaje tomaba su sentido de la historia y práctica de Illinois. Se afirmó que ella era una especie de prohibición criminal de injurias proferidas por escrito (libel) en contra de grupos de personas. Asimismo, el Máximo Tribunal consideró, siguiendo el criterio del caso Chaplinsky, descrito en la introducción de este estudio, que existen ciertas formas de discurso que no gozan de la protección de la libertad de expresión, entre los cuales que se encuentra el injurioso. Así, el enfoque original de los Estados Unidos consideraba las palabras que incitaban al odio como una injuria a un colectivo que, por su misma naturaleza, no gozaría de la protección de la libertad de expresión.

El juez Black redactó uno de los votos disidentes de este fallo, con el que concurrió el juez Douglas. En este, después de recordar que Beauharnais pretendía hacer una petición a las autoridades electas, el juez Black consideró que no era prerrogativa del Poder Judicial decidir qué temas podían o no ser discutidos por los estadounidenses. Este voto

15 Este enfoque se sostiene, por ejemplo, en Caso 12/1999 (1999) III 1, de la Corte Constitucional de Hungría.

${ }^{16}$ Caso 12/1999 (1999) III 1, de la Corte Constitucional de Hungría.

${ }^{17}$ Debe recordarse que este artículo utiliza la palabra liberal para referirse a la posición que favorece la libertad de expresión. Por tanto, no debe confundirse con el uso que se le da en los Estados Unidos, donde la palabra liberal es generalmente identificada con el Partido Demócrata.

18 Decisión Marco 2008/913/JAI (2008). Ella da cierta libertad a los miembros de la Comunidad Europea, especialmente en el segundo apartado de su Art. $1^{\circ}$.

19 Aunque ello sí podría decirse de la mayoría. Algunos ejemplos pueden verse en Politoff (1999) pp. 200 202. 
también hizo presente que, a esa fecha, el tema político de la segregación aún no estaba resuelto, y que el mismo tipo de leyes que condenaban a Beauharnais en Chicago, podrían ser utilizadas en otros estados para encarcelar a personas que abogaban por la no segregación. Asimismo, Black afirmó que la amplitud de esta norma era tal, que podría criminalizar la publicación, venta, presentación o exhibición de obras clásicas. Por último, plantea que el voto de mayoría no presta la debida consideración a la libertad de expresión. ${ }^{20}$

A semejanza de lo que sucede en varios países de Europa, el enfoque de Beauharnais permitía limitar fuertemente la incitación al odio. Sin embargo, a través de los años el Poder Judicial fue manifestando un creciente descontento con estas limitaciones a la expresión, especialmente, porque ciertas normas que prohibían abogar por el uso de medios violentos estaban dirigidas directamente contra el marxismo, actuando como una censura ideológica $^{21}$.

La Corte Suprema modificó su criterio en Brandenburg vs. Ohio (1969). Este caso se refería a un dirigente del Ku Klux Klan que incitó al odio entre los miembros de su grupo, cuestión que fue filmada y divulgada a través de medios de comunicación. Dicho dirigente fue condenado por un tribunal inferior en virtud de una norma que prohibía, entre otras cosas, abogar por la utilización del crimen, sabotaje, violencia o métodos de terrorismo como medios para lograr la reforma industrial o política. En tal caso, la Corte consideró que el simple hecho de abogar por el uso de la violencia no era algo que pudiera ser penado sin vulnerar la garantía constitucional de la Primera Enmienda ${ }^{22}$, y que este tipo de expresión solo podría ser prohibida si estaba "dirigida a incitar o producir inminentemente acciones desenfrenadas (lawless), y es probable que las incite o produzca"23. Este umbral de tolerancia es llamado el estándar de Brandenburg (Brandenburg test) o de la incitación a la violencia inminente ${ }^{24}$. La existencia de este umbral no significa que toda expresión de odio proferida dentro de sus límites esté permitida, pues es posible regular razonablemente el discurso en cuanto al momento, lugar y modo en que se manifiesta ${ }^{25}$; por ejemplo, cuando la audiencia está cautiva ${ }^{26}$.

Así, con el caso Brandenburg se comienzan a proteger las ofensas públicas, con tal que quien las profiera no haya mentido voluntariamente y no exista un peligro claro y presente de violencia o insurrección ${ }^{27}$. Posteriormente, la Corte de Apelaciones invalidó, en el caso Collin vs. Smith (1978), una ordenanza municipal que prohibía demostraciones

\footnotetext{
${ }^{20}$ El juez Black, antiguo senador demócrata, entendía la Primera Enmienda literalmente, como una prohibición - prácticamente absoluta- de toda limitación a la libertad de expresión. Fiss (1995) pp. 282 y 283.

21 Ver Fiss (1995) pp. 285-286. Cfr. con la opinión concurrente del juez Douglas en Brandenburg vs. Ohio (1969) p. 452.

${ }^{22}$ La parte relevante de la Primera Enmienda puede leerse en supra nota 4.

${ }^{23}$ Brandenburg vs. Ohio (1969) p. 447.

${ }^{24}$ Una crítica sobre el requisito de la inminencia puede verse en ReDish (1982) pp. 1180-1182. La opinión disidente del juez Douglas en Beauharnais v. People State of Illinois (1952) Nº 68, podría ser un antecedente de este estándar.

25 Ver Snyder vs. Phelps et al. (2011) p. 10.

${ }^{26}$ Coliver (1992) p. 372.

27 Esta afirmación, y una descripción de la evolución jurisprudencial, puede encontrarse en el fallo canadiense R. vs. Keegstra (1990) pp. 46-48.
} 
públicas que incitaran a la violencia, odio, abuso u hostilidad hacia una persona o grupo de personas por motivos religiosos, étnicos, nacionales o regionales, autorizando así que el partido Nacional Socialista de Estados Unidos se manifestara en Skokie, lugar donde vivía un gran número de judíos ${ }^{28}$. En años más recientes se verán casos como el de R.A.V. vs. City of St. Paul, Minnesota (1992) y Virginia vs. Black (2003), que reiteran que, si bien en algunos casos puede restringirse el hate speech en conformidad con los criterios establecidos por la Corte Suprema, este goza de la protección a la libertad de expresión. En estos casos se sostuvo, por ejemplo, que el discurso que incitara al odio podía ser regulado, a menos que con ello se discriminara según el contenido de la expresión, o se presumiera la intención de incitar al odio por la mera realización de una acción determinada.

El estándar de Brandenburg permite al Estado resguardarse de los llamados a realizar cambios sociales a través de medios no democráticos como la violencia, la revolución y el terrorismo, pero distingue entre el llamado al uso de la violencia y la incitación efectiva a una acción ilegal y violenta inminente, prohibiendo solo esta última ${ }^{29}$. Además, este estándar impide que la autoridad censure ciertos discursos que podrían ser valiosos, pero que son políticamente incorrectos o de dudosa intencionalidad o contenido. Este enfoque es similar al del Pacto de San José de Costa Rica, que en materia de libertad de expresión es más liberal que la Convención Europea de Derechos Humanos y que el Pacto Internacional de Derechos Civiles y Políticos ${ }^{30}$. En efecto, debido a la influencia de Estados Unidos, el Pacto de San José se apartó de la letra de otras convenciones en materia de hate speech, adoptando una redacción más concordante con el estándar de Brandenburg ${ }^{31}$. La Corte Interamericana no ha tenido aún la oportunidad de pronunciarse en esta materia. Sin embargo, atendida su constante posición favorable a la libertad de expresión, y el tenor del texto de la Convención, la Corte debiera tener una opinión más liberal que la de otros tribunales internacionales ${ }^{32}$.

En el caso Snyder vs. Phelps et al. (2011), en materia de responsabilidad civil, la Corte Suprema de Estados Unidos volvió a manifestar su enfoque liberal frente a la libertad de expresión. En este caso la Corte confirmó una sentencia que había revocado un fallo que ordenaba a unos manifestantes pagar varios millones de dólares como indemnización

\footnotetext{
${ }^{28}$ Coliver considera que el mismo principio que autorizó a los nazis a marchar por Skokie es el que habría permitido a Martin Luther King, Jr. marchar por determinados barrios de blancos. Coliver (1992) p. 373.

${ }^{29}$ Knechtle (2006) pp. 548 y 566. Sin embargo, en el mismo Estados Unidos algunos están empezando a poner en duda el requisito de peligro inminente en casos relacionados con la "guerra contra el terrorismo". Ibid. p. 571. La Corte de Apelaciones de EE.UU. sostuvo en Rice vs. Paladin Enterprises (1997) que la inminencia es un requisito para prohibir expresiones que apoyen en forma abstracta la comisión de actos ilegales, no aquellas que entreguen un apoyo técnico para hacerlo, las que sí pueden ser censuradas.

${ }^{30}$ Incluso, esta postura liberal ha recibido algunas críticas en nuestra doctrina, v. gr., Miguel Ángel Fernández muestra su disconformidad con que la Corte no permita que tribunales internos prohíban ex ante ciertas expresiones, como una forma de resguardar otros derechos fundamentales. Fernández GonzÁlez (2001) pp. 389-391.

${ }^{31}$ El párr. 5 del Art. 13 habla de prohibir propaganda que constituya "incitaciones a la violencia o cualquier otra acción ilegal similar..." (el destacado es nuestro). Sobre la historia y alcance de esta norma: PAsQuALucCI (2006) pp. 415 y 416. En este sentido, la Declaración de Principios sobre Libertad de Expresión, adoptada por la Comisión Interamericana de DD.HH. el año 2000, nada dice sobre la incitación al odio.

32 Ver Bertoni (2006) pp. 572-574.
} 
punitiva y por responsabilidad extracontractual ${ }^{33}$. El hecho que motivó este caso fue, a grandes rasgos, que los miembros de una iglesia utilizaron el funeral de un marine muerto en Irak para protestar en contra de los Estados Unidos por su tolerancia de la homosexualidad -especialmente en sus Fuerzas Armadas-, en contra de los sacerdotes católicos y en contra de los homosexuales ${ }^{34}$.

Al momento de dictar su sentencia absolutoria, la Corte Suprema consideró que las expresiones de los manifestantes demandados se encontraban protegidas por la Primera Enmienda, ya que, según estableció el fallo confirmado, se referían a temas de interés público, no podía probarse su falsedad, y habían sido manifestadas solo a través de retórica hiperbólica ${ }^{35}$. Asimismo, este fallo tuvo en consideración que el acto se llevó a cabo con permiso previo de las autoridades locales, en un espacio público ubicado a una cierta distancia del funeral, y que el demandante solo tomó conocimiento del contenido de tal manifestación a través de un noticiario en televisión. Este fallo tuvo solo un voto disidente, el del juez Alito, quien consideró que las circunstancias del caso -entre ellas, una publicación posterior en un sitio web- mostraban que la expresión de Phelps no buscaba solo referirse a materias de interés público, sino que también atacar directamente a una persona específica por el hecho de ser militar y católica, lo que hacía posible aplicar normas sobre responsabilidad extracontractual ${ }^{36}$. Esta opinión disidente no expresó ningún reparo frente a los dichos referidos en general a los militares, homosexuales y sacerdotes católicos.

Actualmente, uno de los métodos más controvertidos de control del discurso de odio en Estados Unidos son los reglamentos internos de las universidades, que en muchas ocasiones incluyen la prohibición de abogar por el odio o la discriminación ${ }^{37}$. Estos códigos de conducta han sido criticados por varias razones. Una de ellas es su aplicación inversa (reverse enforcement), lo que significa que serían ejecutados justamente en contra de minorías ${ }^{38}$. También se alega que los reglamentos muy intrusivos o estrictos introducen en el ambiente estudiantil censuras contrarias al espíritu de libertad de pensamiento, propio del ideal universitario. Asimismo, se critica su falta de eficacia. Por su parte, los tribunales de Estados Unidos han considerado que diversas regulaciones de universidades públicas han sido violatorias de la libertad de expresión, como las de las Universidades de Michigan y Wisconsin ${ }^{39}$.

Sin perjuicio de lo anterior, en Estados Unidos se sanciona de modo especial los crímenes motivados por el odio discriminatorio (hate crimes), siempre que ello no signifique sancionar a las personas por sus expresiones. Así, la ley Matthew Shepard and James Byrd,

\footnotetext{
33 Snyder vs. Phelps et al. (2011) p. 4.

34 Snyder vs. Phelps et al., pp. 1 y 2.

35 Snyder vs. Phelps et al., p. 4.

36 Snyder vs. Phelps et al., voto disidente del juez Alito, pp. 6-11.

37 Para un estudio de posiciones a favor y en contra de estas regulaciones, ver LYNCH (1999) pp. 613-646.

${ }^{38} \mathrm{~V}$. gr., se afirma que si un blanco y un asiático ofenden a una persona negra por su color, el código será aplicado probablemente al asiático y no al blanco. Otro ejemplo sería que las minorías blancas (v. gr. polacos, irlandeses o italianos) serían privilegiadas por sobre las otras. Se sostiene que estos efectos indeseados también ocurren en ambientes supuestamente contrarios a la discriminación, como en las universidades. Lynch cita varios ejemplos reales. LYNCH (1999) pp. 619-624.

${ }^{39}$ LynCH (I999) p. 614 y Bellacosa (1993) pp. 8 y 7.
} 
Jr. Hate Crimes Prevention Act (2009) sanciona los crímenes recién referidos, pero dedica varias disposiciones a reafirmar que ninguna parte de dicha legislación afectará la garantía consagrada en la Primera Enmienda, ni el derecho a expresar creencias en materia de raza, religión, etc., a menos que ellas estén destinadas a preparar la realización de un acto de violencia física, o a incitar la realización de un acto de violencia física inminente ${ }^{40}$.

El enfoque particularmente liberal de Estados Unidos ha sido objeto de críticas, pero sigue vigente en dicho país. Probablemente, porque tal nación surgió como consecuencia de la disidencia con la autoridad estatal, por lo que existe una desconfianza ante la habilidad de la ley y el Gobierno para distinguir entre los discursos buenos y malos. Además, atendido que la protección de la libertad de expresión ha tenido efectos liberalizadores en la historia estadounidense (por ejemplo, en la lucha por los derechos civiles de las personas de raza negra), las cortes tratan de mirar más allá de la forma odiosa de las expresiones, para notar la preocupación pública que subyace en el elemento formal del discurso de odio ${ }^{41}$.

\subsection{ENFOQUe RESTRICTIVO}

Como contrapartida a la postura liberal frente al discurso de odio y la libertad de expresión, el enfoque restrictivo estima que el hate speech constituye un atentado de suficiente gravedad contra la dignidad humana, por lo que debe limitarse. Esta posición puede entender que el discurso de odio tiene diversos grados, habiendo expresiones que no será necesario penalizar; sin embargo, al contrario del enfoque liberal, que por privilegiar la libertad de expresión restringirá el discurso de odio solo en casos muy graves, el enfoque restrictivo considera que los males derivados del hate speech son suficientemente importantes como para censurarlo, tolerando las palabras ofensivas solo en casos muy excepcionales ${ }^{42}$. Algunos proponentes de este enfoque llegan a sostener que el discurso de odio no está protegido por la libertad de emitir opinión e informar, o que ni siquiera es una verdadera expresión ${ }^{43}$.

Mientras los exponentes del enfoque liberal suelen basarse en nociones como la del "libre mercado de las ideas", los del enfoque restrictivo razonan a partir de los fines de la libertad de expresión. estos afirman que la libertad de expresión tiene ciertas finalidades - por ejemplo, permitir la autorrealización de quien se expresa, posibilitar el proceso democrático, manifestar la dignidad humana o generar un ambiente adecuado para alcanzar

40 Sección 4710, incisos 3, 4, 5 y 6, de la Matthew Shepard and James Byrd, Jr. Hate Crimes Prevention Act (2009).

41 V. gr., el lenguaje usado por militantes del Black Power en contra de la policía -a veces altamente ofensivo y racista- ha sido protegido en EE.UU., mientras que en Inglaterra, miembros de tal grupo estuvieron entre los primeros perseguidos por hate speech. Coliver (1992) p. 372. Estos y otros argumentos sobre las razones de por qué EE.UU. adopta una postura liberal, pueden encontrarse en: Coliver (1992) p. 372 y Brugger (2002) p. 14.

42 El artículo 510 del Código Penal de España es un ejemplo claro de una norma que recoge una aproximación restrictiva frente a la libertad de expresión. Código Penal (España), de 1995.

${ }^{43}$ La Corte Europea de DD.HH. ha sostenido que la negación del Holocausto o la justificación de políticas nazi -que en algunos casos es considerado hate speech- no contaría con la protección de la libertad de expresión, v. gr. Lehideux \& Isorni vs. Francia (1998) párr. 53. 
la verdad-y, por tanto, sería posible limitar un discurso que no sea útil para obtener estos fines. Atendido que el hate speech es de escaso valor para adelantar los fines de la libertad de expresión, se considera que es posible restringirlo en cualquiera de sus manifestaciones ${ }^{44}$.

Podría sostenerse que la postura restrictiva se fundamenta también en la consideración del daño que el hate speech causaría a terceros. Sin embargo, esta ponderación no es exclusiva del enfoque restrictivo, pues la aproximación liberal también la hace al restringir un discurso, con la diferencia de que exigirá más pruebas del perjuicio provocado, y una mayor gravedad del mismo. Por ello, la atención al daño que causa el hate speech no se considerará como un argumento que fundamente una posición restrictiva, sino como uno de los motivos para considerar que la incitación al odio es algo negativo, según se verá más adelante. Lo que sí es propio de algunas manifestaciones del enfoque restrictivo, es considerar que las simples ofensas causan un daño calificable de hate speech, con lo que pueden tender a reprimir el discurso políticamente incorrecto, el que a veces tiene un importante valor social ${ }^{45}$.

El razonamiento a partir de los fines de la libertad de expresión puede verse en el caso canadiense $R$. vs. Keegstra $(1990)^{46}$. En este, la Corte Suprema de Canadá, al analizar la proporcionalidad de la sanción criminal impuesta a un profesor de secundaria que promovía el odio contra los judíos, revisó la relación de su discurso con las finalidades de la libertad de expresión. En un pasaje de particular relevancia, se comparan los razonamientos de los fines de la libre expresión y del libre mercado de las ideas. La Corte sostiene:

"En el corazón de la libertad de expresión yace la necesidad de asegurar que la verdad y el bien común sean alcanzados (...). Como la verdad y la forma ideal de organización política y social pueden raramente, si acaso pudieran, ser identificadas con certeza absoluta, es difícil prohibir la expresión sin impedir el libre intercambio de información potencialmente valiosa. Sin embargo, el argumento de la verdad no provee apoyo convincente para la protección de la propaganda del odio. Llevado al extremo, este argumento requeriría que nosotros permitiéramos la comunicación de toda expresión, pues es imposible saber con absoluta certeza qué declaraciones fácticas son verdaderas ${ }^{47}$, o a partir de qué ideas se puede obtener el bien mayor. El problema con esta posición extrema, sin embargo, es que, a mayor grado de certeza de que una afirmación es errónea o mendaz, menor será su valor en la búsqueda de

\footnotetext{
44 Por ejemplo, pueden afirmar que las incitaciones al odio "no son parte esencial de ninguna exposición de ideas, y son de tan poco valor social como paso hacia la verdad, que cualquier beneficio que pueda derivarse de ellas es claramente sobrepasado por el interés social en el orden y la moralidad". Chaplinsky vs. New Hampshire (1942) p. 572. Debe recordarse que esta sentencia estadounidense ha perdido parte de su fuerza práctica. Algunos fallos citan frases como la copiada, v. gr. Virginia vs. Black (2003), pero lo hacen para fundamentar las restricciones mínimas que se permiten en un ambiente en el que las teorías liberales subyacen como ethos.

45 Lo ofensivo de un discurso puede depender más de susceptibilidades, que de la objetiva nocividad social.

46 Este razonamiento también puede verse en casos que no son de incitación al odio. Por ejemplo, fue uno de los argumentos utilizados por nuestra Corte Suprema al prohibir la exhibición de la película La Última Tentación de Cristo. García Valdés y Otros con Consejo de Calificación Cinematográfica (1997) considerando N 18. ${ }^{47}$ La palabra "absoluta" se encuentra subrayada en el original.
} 
la verdad. Es más, la expresión puede ser usada en detrimento de nuestra búsqueda de la verdad" 48 .

En otras palabras, la Corte afirma que el valor del discurso de odio es bajísimo si se considera a la luz del alcance de la verdad - una finalidad de la libertad de expresión-, y que el argumento del libre mercado de las ideas es insuficiente como para impedir la prohibición del hate speech. Este razonamiento pondera las expresiones y concluye que algunas de ellas, de muy escaso valor, no pueden ser exhibidas en el libre mercado de las ideas.

El razonamiento de dicho tribunal fue fuertemente rechazado por el voto disidente redactado por Beverley McLachlin ${ }^{49}$. Ella sostuvo que, si bien la libertad de expresión no es una garantía de que la verdad triunfará en el libre mercado de las ideas, el ambiente creado por este permite la promoción de la verdad en formas que serían imposibles sin él. También sostiene que los efectos adversos de esa limitación, tanto para el alcance de la verdad como para la creatividad humana, se aprecian al mirar las sociedades donde la libertad de expresión ha sido restringida. Afirma que no es coincidencia que en tales sociedades la verdad sea a veces reemplazada por la imposición de ideas. Por último, sostiene que es errado justificar la garantía de la libertad de expresión solo en la promoción de la verdad, ya que, por muy importante que pueda ser esta, hay opiniones que no pueden ser tenidas por verdaderas o falsas, y que no por ello serán consideradas indignas de todo valor.

El texto constitucional aplicable, y su relación con el discurso de odio, es uno de los factores que influyen en el modo en que los tribunales interpretan la libertad de expresión. En Canadá, la Carta de Derechos y Libertades establece el derecho fundamental a la libertad de expresión sin ningún tipo de restricción específica ${ }^{50}$, pero lo sujeta a la cláusula general de limitaciones, que sostiene que los derechos y libertades están sujetos a las restricciones razonables que estén prescritas por ley, y se muestren como justificadas en una sociedad libre y democrática ${ }^{51}$. Además, la referida Carta sostiene que su texto debe ser interpretado en forma consistente con la preservación y promoción de la herencia multicultural canadiense $\mathrm{e}^{52}$. Tales disposiciones pueden favorecer la restrictiva interpretación canadiense de la libertad de expresión en materia de hate speech. Algo similar sucede con el Tribunal Constitucional Federal Alemán, que también tiene una interpretación restrictiva en materia de incitación al odio, a pesar de la amplia protección de la libertad de expresión en la Ley Fundamental alemana ${ }^{53}$. Ello puede deberse al tenor de las disposiciones constitucionales relativas al derecho al honor, al derecho a la personalidad y al respeto por la dignidad 54 . En contraste, la libertad de expresión ocupa un lugar preeminente en la Constitución de Estados Unidos, sin estar limitada expresamente por ninguna otra

48 Y sigue: "El Estado no debiera ser el único juez de la verdad, pero tampoco debemos exagerar la visión de que la racionalidad sobrepasará todas las falsedades en un mercado de las ideas que no esté regulado". $R$. vs. Keegstra (1990) pp. 69 y 70.

49 R. vs. Keegstra (1990) pp. 103 ss. Ella es la actual presidenta de la Corte Suprema de Canadá.

50 Art. 2 letra b) de la Canadian Charter of Rights and Freedoms (1982).

51 Canadian Charter of Rights and Freedoms (1982), Art. 1.

52 Canadian Charter of Rights and Freedoms (1982), Art. 27.

53 Art. 5 Inc. 1 de la Ley Fundamental de la República Federal de Alemania (1949).

54 Arts. 5 Inc. 2; 2 Inc. 1, y 1 Inc. 1, respectivamente. Ver Brugger (2002) p. 7. 
garantía fundamental ${ }^{55}$. Sin perjuicio de todo lo anterior, el texto constitucional no es determinante en la posición adoptada por los tribunales de un determinado país, ya que, por ejemplo, la Constitución de Hungría contiene algunas disposiciones similares a las alemanas, y no obstante ello tiene un enfoque que puede ser considerado liberal ${ }^{56}$.

Al igual como sucede en Estados Unidos, la historia juega un papel muy relevante en los países que tienen un enfoque restrictivo de la libertad de expresión. Por ejemplo, los efectos del nazismo han motivado muchas normas contra la incitación al odio en Europa. En efecto, ya desde antes de que se tomara conocimiento del Holocausto, la simple existencia de esta ideología en Alemania provocó la dictación de normas penales como la danesa y la francesa, ambas de $1939^{57}$. Posteriormente, una vez conocidos los crímenes genocidas nazis, algunos países dieron una especial protección al judaísmo, o empezaron a considerar la negación del Holocausto como una forma especial de incitación al odio. Sin perjuicio de lo anterior, el nazismo no ha sido el único catalizador de este tipo de normas, pues en varios países ellas se encontraban vigentes con anterioridad al surgimiento de esta ideología ${ }^{58}$.

\subsection{Regulación de la incitación al odio en Chile}

Actualmente, la única norma que dice relación directa con el hate speech en Chile es el artículo 31 de la ley sobre Libertades de Opinión e Información y Ejercicio del Periodismo, que dispone:

"El que por cualquier medio de comunicación social, realizare publicaciones o transmisiones destinadas a promover odio u hostilidad respecto de personas o colectividades en razón de su raza, sexo, religión o nacionalidad, será penado con multa de veinticinco a cien unidades tributarias mensuales. En caso de reincidencia, se podrá elevar la multa hasta doscientas unidades tributarias mensuales" 59 .

Como puede observarse, esta norma no requiere la creación de un efecto objetivo en los oyentes para ser aplicada, ni delimita lo que entiende por "odio u hostilidad", por lo que podría calificarse como una norma de enfoque restrictivo. Sin embargo, atendido que exige que el emisor del discurso busque promover el odio u hostilidad, sin que basten conductas que lo provoquen sin quererlo, y que tolera las expresiones que no sean realizadas en medios de comunicación social, puede decirse que esta disposición adopta una posición intermedia, no restrictiva ni liberal, aunque inclinada hacia la primera. Esta norma tiene su antecedente en la antigua Ley sobre Abusos de Publicidad, que castigaba a

\footnotetext{
55 Brugger (2002) p. 7.

${ }^{56}$ Las normas constitucionales relevantes son las siguientes: Art. 54 Inc. 1 (derecho a la dignidad), Art. 59 Inc. 1 (derecho a la reputación) y Art. 61 Inc. 1 (libertad de opinión e información). Constitución de la República de Hungría (1949), ampliamente reformada en 1989.

57 Ver, respectivamente, Johannessen (1992): “Denmark...”, p. 140, y Errera (1992) 144 y 145.

58 V. gr. Hungría. Cfr. Caso 12/1999 (1999) II, 3.2.

59 Ley $N^{\circ} 19.733$ (2001). Sin embargo, esta no es la única norma referida al "odio" en cuanto tal. Por ejemplo, el artículo 126 del Código Penal hace referencia a "actos de odio" realizados "en la persona o bienes de alguna autoridad o de sus agentes o en las pertenencias del Estado o de alguna corporación pública”.
} 
quienes "realizaren publicaciones o transmisiones que conciten el odio, la hostilidad o el menosprecio respecto de personas o colectividades en razón de su raza o religión" 60 . Hasta el momento, la disposición vigente ha sido aplicada en una sola sentencia, que será descrita más adelante.

Además de la anterior, existen normas que no se refieren específicamente a la incitación al odio, sino que a la discriminación arbitraria. estas se relacionan indirectamente con el hate speech, pues pueden ser aplicadas a actos de discriminación que tengan la intención de incitar al odio. Una de estas normas es el artículo 19 número $2^{\circ}$ de la Constitución, que reconoce un derecho garantizado con la acción de protección. Otra norma importante está establecida en el artículo octavo de la llamada Ley Indígena, que dispone que "Se considerará falta la discriminación manifiesta e intencionada en contra de los indígenas, en razón de su origen y cultura" 61 .

No está de más señalar que el ordenamiento jurídico chileno contó con una norma de rango constitucional relativa a la incitación al odio. Tal disposición estaba inserta en el primer inciso del controversial artículo octavo de la Constitución Política de 1980 en su versión original ${ }^{62}$. La parte relativa al hate speech establecía: "Todo acto de persona o grupo destinado a propagar doctrinas que [...], propugnen la violencia [...], es ilícito y contrario al ordenamiento institucional de la República"63. Esta norma no exigía que la violencia se dirigiera en contra de grupos de personas. Sin embargo, eso no le quita su carácter de regulación de la incitación al odio, ya que, en la práctica, las "doctrinas" que propugnan la violencia (v. gr. comunismo o nazismo), siempre apuntan en contra de grupos específicos ${ }^{64}$.

El primer inciso del artículo octavo de la versión original de la Constitución podría haber sido considerado, en general, como una norma restrictiva. Sin embargo, la parte relacionada exclusivamente con el hate speech-citada en el párrafo anterior-, era de un talante liberal, al menos en cuanto al contenido del discurso, pues toleraba el hate speech que no incitara a la violencia. Como se sabe, el artículo octavo fue muy controvertido ${ }^{65}, y$, en definitiva, derogado. No obstante ello, parte de él pasó -en la reforma de 1989- al actual inciso sexto del número $15^{\circ}$ del artículo 19 de la Constitución ${ }^{66}$, pero el resultado de

${ }^{60}$ Lo establecía en su derogado artículo 18. Ley No 16.643 (1967).

${ }^{61} \mathrm{Tal}$ conducta se sanciona "con multa de uno a cinco ingresos mínimos mensuales". Ley No 19.253 (1993). Otras disposiciones sobre la discriminación arbitraria pueden verse en Cisternas Reyes (2004) pp. 425-430.

${ }^{62} \mathrm{Tal}$ artículo buscaba establecer un "pluralismo limitado". Cea Egaña (1981) p. 19.

${ }^{63} \mathrm{El}$ inciso completo disponía: "Todo acto de persona o grupo destinado a propagar doctrinas que atenten contra la familia, propugnen la violencia o una concepción de la sociedad, del Estado o del orden jurídico, de carácter totalitario o fundada en la lucha de clases, es ilícito y contrario al ordenamiento institucional de la República”. Ribera Neumann (1985) pp. 265 y 266. Tal estudio contiene un análisis muy acabado sobre dicha norma.

${ }^{64}$ En efecto, cuando Ribera se refiere a esta prohibición de la violencia, expone la relación entre ella y las normas sobre el hate speech de la Convención Americana sobre Derechos Humanos y del Pacto Internacional de los Derechos Civiles y Políticos. Ribera Neumann (1985) p. 271.

65 V. gr., su retroactividad. Ribera NeumanN (1985) pp. 274 y 275.

${ }^{66}$ La parte relevante establece: "Son inconstitucionales los partidos, movimientos u otras formas de organización [...] que hagan uso de la violencia, la propugnen o inciten a ella como método de acción política. Corresponderá al Tribunal Constitucional declarar esta inconstitucionalidad". 
dicha disposición es de una especificidad tal, que más bien debe ser considerada una regulación de la actividad política en el país.

Actualmente existe un proyecto de ley bastante avanzado que busca consagrar como delito penal la promoción del odio. Se trata del llamado "Proyecto de Ley que Establece Medidas contra la Discriminación” ${ }^{67}$, que, al momento de redactarse el presente artículo, agregaría al Código Penal un nuevo párrafo titulado "De los delitos contra la igualdad de las personas, en dignidad y derechos”. Dicha sección contendría el siguiente artículo único:

"Artículo 137 bis. El que promueva el odio u hostilidad en contra de una persona o un grupo de personas en razón de su raza, sexo, religión o nacionalidad, será penado con multa de cinco a cien unidades tributarias mensuales. En caso de reincidencia, se podrá elevar la multa hasta doscientas unidades tributarias mensuales" 68 .

La recién citada norma no se encontraba en el proyecto de ley original, sino que fue inspirada en una moción anterior denominada "Sobre Discriminación Racial y Étnica", actualmente archivada, que a lo largo de su tramitación fue incorporando un extenso listado de propuestas en esta materia ${ }^{69}$. De aprobarse la redacción actual del proyecto de ley en tramitación, nuestro ordenamiento jurídico se alejaría de la posición intermedia que ha adoptado hasta el momento en materia de hate speech, inclinándose hacia una postura restrictiva. esta incumpliría algunos de los requisitos que, a nuestro entender, debiera tener una legislación adecuada de prohibición de la incitación al odio, según se verá más adelante en este estudio.

El referido proyecto también busca establecer la siguiente circunstancia agravante en el artículo 12 del Código Penal: "210: Cometer el delito fundado por motivo de discriminación arbitraria”70. Esta disposición no consiste estrictamente en una regulación de la incitación al odio. En este sentido, la Corte Suprema de Estados Unidos, no obstante su postura contraria a la regulación del hate speech, ha considerado que normas de este tenor no estarían en conflicto con la libertad de expresión ${ }^{71}$. Ello, porque dichas disposiciones no sancionan creencias abstractas del delincuente, sino que solo toman en cuenta sus motivos particulares para delinquir, los que siempre han sido considerados al momento de calificar la pena, por ejemplo, al agravar la sanción cuando ha habido una motivación económica ${ }^{72}$. Algo similar sucedería en nuestro país, según se puede apreciar en el listado de circunstancias agravantes y atenuantes establecidas en el Código Penal ${ }^{73}$.

\footnotetext{
${ }^{67}$ Boletín $\mathrm{N}^{\circ} 3815-07$.

${ }^{68}$ Art. 137 bis, Párrafo 1 bis, inserto en el Título III del Libro II. Comisión De DD.HH. (2008) p. 42.

${ }^{69}$ Proyecto de Ley sobre Discriminación Racial y Étnica. Boletín 2142-17. La incorporación de estas normas penales hizo que su nombre cambiara a "Proyecto que Penaliza los Actos de Discriminación”.

70 Art. $9 \mathrm{~N}^{\circ}$ 1. Comisión de DD.HH. (2008) p. 42.

71 Ver Wisconsin vs. Mitchell (1993). Cfr. Sección 280003 de la Violent Crime Control and Law Enforcement Act (1994).

72 Wisconsin vs. Mitchell (1993) p. 585. Ver también Nota (1993) "Hate Is Not Speech...", de fecha anterior a la dictación del fallo recién citado.

${ }^{73}$ V. gr. Art. 11, $\mathrm{N}^{\circ} \mathrm{s} 4$ y 10 , y Art. $12 \mathrm{~N}^{\circ} 2$.
} 
La legislación vigente en Chile ha tenido muy escasa aplicación. En efecto, el año 2010 se dictó el primer fallo en la materia, recaído en un proceso seguido por el Ministerio Público de Villa Alemana en contra de Elliot Quijada ${ }^{74}$, a quien se sancionó por dos cargos, uno de los cuales fue la infracción del artículo 31 de la Ley sobre Libertades de Opinión e Información y Ejercicio del Periodismo ${ }^{75}$.

El Tribunal consideró que el imputado realizó los siguientes hechos: atribuir al presidente de la comunidad judía en Chile, a través de internet, "declaraciones en contra del pueblo palestino"76; "confeccionar afiches y panfletos con la imagen trucada o modificada de doña Lily Pérez San Martín en las cuales se la ridiculizaba y menoscababa en su calidad de judía, afirmando que la parlamentaria era agente del Estado de Israel"77; publicar en internet expresiones antisemitas y otras en que se vinculaba a la señora Pérez, por "su calidad de integrante de la colectividad judía”, "con supuestas actividades de tipo extremista, terrorista y racista"78; lanzar a la parlamentaria, durante una gira electoral, gritos ofensivos basados en su religión, acciones que fueron grabadas y subidas a una página de internet ${ }^{79}$; haber formado parte de un grupo que acosó a la señora Pérez durante su campaña política ${ }^{80}, y$, por último, distribuir panfletos entre los habitantes de la zona electoral de la parlamentaria, en los que se superponía una esvástica a la estrella de David, y se representaba a la señora Pérez haciendo "un saludo nazi, con brazaletes de esvásticas y estrellas de David" 81 . Algunos de estos hechos acreditados no forman parte de la definición de la infracción según la normativa vigente, por lo que no fueron tenidos en cuenta al momento de señalar los hechos ajustados al tipo penal ${ }^{82}$.

La defensa planteó dos puntos jurídicos que conviene mencionar. El primero fue que internet no podía ser considerada un medio de comunicación social. Frente a ello, basándose en la amplia definición de medio de comunicación social establecida en el artículo segundo de la ley 19.733, el tribunal sostuvo que "lo que constituye un medio de comunicación social no es Internet propiamente tal (aun cuando ello es también actualmente motivo de controversia, especialmente en la misma web) sino que los sitios o páginas que en ella existen, en la medida que ellas cumplan los requisitos del artículo $2^{\circ}{ }^{\prime 3}$. El siguiente punto dice relación con la libertad de expresión, ya que la defensa trató de exponer una visión liberal de esta, especialmente, porque los hechos se dieron en el contexto de una contienda electoral. Sin embargo, el tribunal adoptó una interpretación restrictiva. Al hacerlo, el tribunal citó, entre otras cosas, la Convención Americana sobre Derechos Huma-

\footnotetext{
${ }^{74}$ Ministerio Público de Villa Alemana contra Quijada Avilés (2010). Este fallo se encuentra ejecutoriado.

75 La condena por esta infracción fue de cincuenta unidades tributarias mensuales. Ministerio Público de Villa Alemana contra Quijada Avilés (2010) p. 61.

76 Ministerio Público de Villa Alemana contra Quijada Avilés (2010) p. 38.

77 Ministerio Público de Villa Alemana contra Quijada Avilés (2010).

78 Ministerio Público de Villa Alemana contra Quijada Avilés (2010).

${ }^{79}$ Ministerio Público de Villa Alemana contra Quijada Avilés (2010) pp. 40 y 51.

80 Ministerio Público de Villa Alemana contra Quijada Avilés (2010) p. 40.

${ }^{81}$ Ministerio Público de Villa Alemana contra Quijada Avilés (2010).

${ }^{82}$ Ver considerando decimocuarto. Ibid., pp. 43-51.

83 Ministerio Público de Villa Alemana contra Quijada Avilés (2010) p. 45. El desarrollo de este argumento puede verse entre las páginas 43 y 46.
} 
nos, a pesar de que dicho tratado tiene una redacción influenciada por la posición liberal de Estados Unidos.

En su declaración, el acusado afirmó que él no habría atacado al judaísmo, sino que al sionismo ${ }^{84}$. Las circunstancias del caso -como los gritos contra la senadora por su calidad de judía- permitirían haber argumentado que la postura antisionista del acusado era solo un modo de disfrazar su antijudaísmo. Sin embargo, el tribunal no utilizó esta vía, sino que desechó el argumento del señor Quijada mediante una identificación de los conceptos de judaísmo y sionismo, sosteniendo que los acusados consideraban que ser judío equivaldría a ser sionista ${ }^{85}$. Esta identificación no está debidamente fundamentada, y podría ser restrictiva de la libertad de expresión de quienes, sin tener ninguna antipatía contra los judíos, consideren inadecuado el ideario político de restablecer Palestina como patria del pueblo hebreo ${ }^{86}$.

Sin perjuicio de lo anterior, el fallo logra un resultado jurídicamente adecuado, pues la publicación en internet de imágenes asociando un emblema del judaísmo -la estrella de David- con símbolos odiosos como calaveras y esvásticas, es un acto susceptible de ser sancionado según la ley $19.733^{87}$.

\section{PROS Y CONTRAS DE LA PENALIZACIÓN DE LA INCITACIÓN AL ODIO}

El apartado que ahora comienza revisará brevemente los efectos negativos del hate speech, para luego enunciar los argumentos a favor y en contra de las normas que penalizan la incitación al odio. Es muy importante hacer estas consideraciones al decidir si se legisla sobre una materia y, en caso de hacerlo, para determinar el contenido de tal normativa. Por eso, llama la atención que en la discusión sobre la conveniencia del proyecto de ley actualmente en tramitación, solo se hiciera referencia a cierta legislación comparada en la materia y a los males de la discriminación e incitación al odio, pero no a los pros y contras de este tipo de normas, ni a su efectividad ${ }^{88}$.

\subsection{Efectos negativos de la incitación AL Odio}

No es poco frecuente que quienes abogan por la criminalización del hate speech, en vez de dar razones sobre la conveniencia de tal penalización, fundamenten su argumentación en la malicia de la incitación al odio. Por ello, conviene hacer una distinción entre ambas cuestiones, pues tanto la posición liberal como la restrictiva entienden la negatividad que puede encerrar la incitación al odio. La controversia se produce únicamente en cuanto a si la proscripción del hate speech-generalmente mediante la ley penal- es un arma adecuada y prudente para combatirlo. Un modo de ejemplificar esta distinción sería imaginando un debate ficticio sobre la conveniencia de criminalizar la mentira. En

\footnotetext{
${ }^{84}$ Ministerio Público de Villa Alemana contra Quijada Avilés (2010) pp. 14-16.

85 Ministerio Público de Villa Alemana contra Quijada Avilés (2010) p. 47. Ver también pp. 25 y 28.

${ }^{86}$ Cfr. con la definición de sionismo del Diccionario de la R.A.E.

${ }^{87}$ Ministerio Público de Villa Alemana contra Quijada Avilés (2010) p. 40.

${ }^{88}$ Ver Comisión de DD.HH. (2005), especialmente pp. 19 ss.
} 
dicha disputa, ambos bandos estarían probablemente de acuerdo en que la mentira es algo moralmente reprochable; en que existen algunos engaños más graves que otros, y en que algunos de ellos pueden llegar a afectar la integridad moral, física o económica del perjudicado. Por ello, el debate debiera centrarse únicamente en determinar si existen mentiras suficientemente graves como para criminalizarlas, y en caso de ser así, en resolver qué requisitos y excepciones se aplicarán en dicha penalización.

En efecto, no hay duda de que el discurso de incitación al odio puede tener consecuencias muy negativas, aunque las circunstancias en las que se profiere tendrán un papel decisivo en su gravedad. No es lo mismo, por ejemplo, que un personaje influyente incite al odio a masas enardecidas en un momento histórico de grandes convulsiones sociales, que proferir un discurso de odio exclusivamente ante miembros del grupo objeto del hate speech, o únicamente ante personas que no son capaces de entenderlo.

Las consecuencias negativas de la incitación al odio son variadas. Por ejemplo, puede afectar el honor o la dignidad de un grupo en forma similar a aquella en que se menoscaba el de una persona que es difamada. Asimismo, puede favorecer las discriminaciones arbitrarias en contra del colectivo objeto de este discurso ${ }^{89}$, afectando la equidad y el multiculturalismo ${ }^{90}$. Por último, la incitación al odio cometida a través de medios de comunicación masiva puede llegar a tener efectos gravísimos, como han reconocido el Tribunal de Núremberg ${ }^{91}$ y el Tribunal Penal Internacional para Ruanda. ${ }^{92}$ Estos últimos casos son extremos, pues en ellos se incitaba al genocidio en los medios de comunicación ${ }^{93}$. En cambio, la regla general será que la incitación al odio no llame al exterminio ni tenga efectos directamente observables. En efecto, en contextos restrictivos de la libertad de expresión se ha llegado, incluso, a considerar como hate speech la exposición de ciertas opiniones o la negación de hechos históricos ${ }^{94}$.

En resumen, es claro que la incitación al odio puede afectar los derechos del grupo objeto de este discurso en forma más o menos grave. En casos extremos, la libertad de expresión de unos pocos puede contribuir, incluso, a dañar físicamente a determinadas minorías. Sin embargo, la protección del honor y de la dignidad e integridad física de los afectados por el hate speech, la promoción de la equidad y el multiculturalismo, etc., son

${ }^{89}$ El Art. 510 del Código Penal español busca prohibir la incitación a la discriminación. Lo mismo sucede con los Arts. 225-1 al 225-5 del Código Penal francés, que establecen delitos de discriminación en el capítulo de atentados contra la dignidad de las personas. Código Penal (España) (1995) y Code Pénal (Francia) (2010), respectivamente.

${ }^{90} \mathrm{El}$ multiculturalismo es uno de los valores más proclamados en Canadá al momento de restringir el discurso de odio. Cfr. Art. 27 de la Canadian Charter of Rights and Freedoms (1982).

${ }^{91}$ Trial of the Major War Criminals before the International Military Tribunal (1946), en particular la parte de la sentencia relativa a Julius Streicher (pp. 547-549). Sobre la relación entre incitación al odio y genocidio ver Schabas (2000).

92 Ver The Prosecutor v. Jean-Paul Akayesu (1998) párrs. 672-675.

${ }^{93}$ El Art. 3 letra c) de la Convención para la Prevención y la Sanción del Delito de Genocidio prohíbe la "instigación directa y pública a cometer genocidio", la forma más extrema de hate speech. En el caso de Ruanda ver Schabas (2000) p. 146 y Knechtle (2006) p. 547.

${ }^{94}$ Los casos más típicos serán los delitos de negación del Holocausto o de otros crímenes contra la humanidad. V. gr., el artículo 9 de la Ley Gayssot. Loi Tendant à Réprimer Tout Acte Raciste, Antisémite ou Xénophobe (1990). 
razones que servirían para debatir sobre los efectos negativos de la incitación al odio -materia en la que existe un amplio acuerdo entre los enfoques restrictivo y liberal-, no para discutir sobre la conveniencia o efectividad de su penalización.

\subsection{Argumentos en el debate sobre la penalización de la incitación al ODIO}

En este apartado se repasarán algunos de los argumentos a favor y en contra de la penalización de la incitación al odio, procurando no confundirlos con aquello atingentes a la malicia del hate speech. Este examen podría haberse hecho exponiendo por separado los motivos de cada una de las posiciones opuestas, pero se hará analizando ambas posturas bajo los mismos títulos, mostrando qué opina cada posición frente a un determinado tema. Esta sección solo busca repasar los pros y contras argüidos en este debate, sin adoptar necesariamente una posición sobre ellos, a diferencia de lo que se hará en la sección siguiente, al proponer los requisitos que debiera tener una norma que regule el hate speech.

\section{a. Relación con la libertad de expresión}

La primera controversia en el debate sobre la prohibición del hate speech se refiere a la relación de este discurso con la libertad de expresión. Esta relación es compleja, pues, según ha dicho el Tribunal Europeo de Derechos Humanos -cuya postura podría ser calificada de restrictiva-, el derecho a la libertad de expresión "es válido no solo para las informaciones o ideas que son favorablemente recibidas o consideradas como inofensivas $\mathrm{o}$ indiferentes, sino también para aquellas que chocan, inquietan u ofenden al Estado o a una fracción cualquiera de la población"95. En efecto, la garantía constitucional que ampara la libertad de expresión busca, justamente, proteger discursos que puedan resultar inquietantes o molestos para algunos sectores de la población, ya que son estos los que tratarán de ser apagados por sus detractores. El problema está en determinar qué discurso se halla dentro de las expresiones que deben ser toleradas en virtud de las demandas de una sociedad democrática. Atendido que las afirmaciones de ambas posturas en este tema ya han sido descritas, no será necesario referirse a ellas nuevamente.

\section{b. Efecto intimidatorio}

La postura liberal frente a la incitación al odio sostiene que una ley penal que prohíba el hate speech-especialmente si está deficientemente definida- puede tener un efecto intimidatorio o inhibitorio (chilling effect) en discursos que los legisladores no buscaban prohibir, afectando expresiones que podrían ser dignas de aprecio. Así, podría inhibirse la difusión de obras clásicas, como "El Mercader de Venecia"96, o modernas, como "El Có-

\footnotetext{
95 Afirmado por el Tribunal Europeo de DD.HH. en casos como Handyside vs. Reino Unido (1976), y citado en castellano por la Corte Interamericana de DD.HH. en Olmedo Bustos y Otros vs. Chile (La Última Tentación de Cristo) (2001) párr. 69.

${ }^{96}$ Ejemplo propuesto en el caso Collin vs. Smith (1978) p. 1207. El voto de minoría del caso R. vs. Keegstra (1990) comparte esta preocupación en p. 168. La Corte Suprema de Canadá también manifestó su aprensión sobre el efecto intimidatorio (chilling efect) frente a una norma que sancionaba a quienes propagaran noticias sabidamente falsas, que pudieran causar algún daño a terceros. $R$. vs. Zundel (1992) pp. 50-52.
} 
digo Da Vinci" o "Tintín en el Congo". Este efecto intimidatorio no es exclusivo de leyes sobre el hate speech, pues puede también ser producido por otras normas, como las relativas a la difamación, que en caso de ser muy abiertas pueden disuadir de la simple crítica a autoridades públicas.

Frente a esta objeción, quienes tienen una postura restrictiva de la libertad de expresión pueden sostener que, en materia de incitación al odio, es preferible evitar expresiones simplemente ofensivas, antes que permitir palabras que en forma velada inciten al odio. Sin embargo, los efectos de actos susceptibles de ser catalogados como incitación al odio podrían, en algunos casos, ser menos graves que los producidos por otros abusos de la libertad de emitir información y de informar, por lo que este argumento pro restricción podría ser extendido a cualquier bien jurídico vulnerable por el abuso de la expresión. Por ello, quienes sostienen este argumento debieran estar también de acuerdo con el uso de la ley penal en la protección de, por ejemplo, la honra de las personas y su privacidad. Así, si este razonamiento pro restricción se aplicara consistentemente, el contenido de la libertad de expresión podría verse muy afectado.

La postura restrictiva también puede afirmar que, para evitar el efecto intimidatorio, bastaría con hacer una ley acotada o que contemple excepciones adecuadas. Esta afirmación desconocería lo difícil que es delimitar claramente los efectos de una ley, especialmente si se refiere al hate speech, ya que la misma definición de odio es muy imprecisa. Por otra parte, si una norma de prohibición de la incitación al odio es amplia, las excepciones que la limiten también lo serán. Un ejemplo de esto se halla en la ley sobre odio racial y religioso de Inglaterra y Gales ${ }^{97}$, cuya prohibición del hate speech tiene una excepción que reza así:

"Ninguna parte de esta sección será interpretada o ejecutada de modo que prohíba o restrinja la discusión, crítica o expresiones de antipatía, aversión, burla, insulto $\mathrm{u}$ ofensa de religiones en particular o creencias, o prácticas de sus adherentes, o de cualquier otro sistema de creencias o prácticas de sus adherentes, o el proselitismo, o el urgir a los adherentes de otras religiones o sistemas de creencias a que cesen de practicar su religión o sistema de creencias" 98 .

Esta extensa excepción busca separar el discurso dirigido en contra de personas en virtud de su religión o sistema de creencias, de la crítica a las creencias mismas. Sin embargo, no es fácil determinar si ella cumple con su objetivo o, si en vez de ello, termina anulando los efectos de la prohibición de la incitación al odio religioso.

Por último, la estrecha relación que existe entre la libertad de expresión y otros derechos que requieren de ella, hace que el efecto inhibitorio también los afecte a estos. En efecto, regulaciones restrictivas han afectado también la libertad de asociación, como

97 Racial and Religious Hatred Act (2006).

${ }^{98}$ Esta excepción se titula "Protección de la Libertad de Expresión", y fue insertada por la Racial and Religious Hatred Act en la Ley sobre Orden Público, bajo el número 29(J). 
hacían las normas dirigidas en contra del comunismo ${ }^{99}$, y la libertad de religión, como sucedió en el caso de Åke Gregen, un pastor pentecostal sueco que fue condenado en primera instancia - pero posteriormente absuelto- por dar un sermón en que criticaba la homosexualidad $^{100}$.

\section{c. Efecto educativo de la ley}

No es fácil negar el efecto educativo de la legislación, especialmente cuando ella se encuentra asociada a la imposición de una pena. Un ejemplo de lo anterior puede darse con las normas del tránsito efectivamente aplicadas. Estas logran que la población conozca las acciones que conllevan la imposición de una multa, las difundan entre sus conocidos, y eviten cometer la infracción en lugares en que puedan ser sorprendidos. La posición restrictiva frente a la libertad de expresión podría considerar que la prohibición del hate speech, al reflejar el interés del Estado en el combate de tal discurso, educará a la población sobre su gravedad ${ }^{101}$.

Quienes tienen un enfoque liberal frente a la libertad de expresión notan que la prohibición de la incitación al odio se establece generalmente en normas criminales, cuya finalidad primaria no es educar, sino que sancionar. En efecto, tales normas son consideradas por la doctrina jurídica como la ultima ratio, pues "[e]l aparato penal constituye la herramienta más severa con que cuenta el Estado (...), para enfrentar conductas que atentan gravemente (...) contra la vida de la comunidad y los derechos primordiales de sus integrantes" 102 . Por ello, opinan que la prohibición de la incitación al odio no debiera fundamentarse en el supuesto efecto educativo de la ley.

Como respuesta a la objeción planteada por el enfoque liberal, puede sostenerse que la prohibición de la incitación al odio no siempre estará consagrada en normas penales. Un caso útil para ilustrar esta situación es Canada (Human Rights Commission) vs. Taylor (1990), donde se castigó a una persona en virtud de la Ley Canadiense de Derechos Humanos, que en una de sus disposiciones prohíbe comunicar telefónicamente mensajes que pudieran exponer al odio a una persona o grupo ${ }^{103}$. En este caso, la Corte consideró que el perjuicio provocado por la sanción impuesta no sería excesivo, pues, mientras la aplicación de leyes criminales crea fácilmente estigmas sociales, las normas de derechos humanos tendrían una función más conciliadora, que buscaría evitar discriminaciones ${ }^{104}$. Dicho

\footnotetext{
99 Ya referidas al describir el antiguo enfoque restrictivo de Estados Unidos.

${ }^{100}$ La sentencia fue definitivamente revocada por la Corte Suprema de Suecia, que consideró que aquella estaba en conflicto con normas internacionales como la Convención Europea de DD.HH. HousER (2009) p. 613.

${ }^{101}$ Ello, sin perjuicio de que no utilice la palabra "educación" para designar a este efecto. Por ejemplo, Politoff lo llama "significado simbólico". Politoff (1999) p. 212. Una breve crítica al uso eminentemente pedagógico o simbólico del Derecho penal puede encontrarse en Carnevalli Rodríguez (2008) p. 37.

102 Voto concurrente del Juez S. García en el caso Herrera Ulloa vs. Costa Rica (2004), párr. 15. En el mismo sentido: Caso Kimel vs. Argentina (2008) párr. 76, y Corte Constitucional de Hungría, Caso 18/2004 (2004) V 2.2. En materia de ultima ratio, es especialmente interesante CARnEvalli Rodríguez (2008).

103 Sección 13, Inc. 1 de la Canadian Human Rights Act (2009).

104 Canadá (Human Rights Commission) vs. Taylor (1990) p. 29. En este caso se reclamó sobre la constitucionalidad de la norma utilizada, pero la Corte Suprema de Canadá consideró que, al no haberse aplicado una ley penal, era posible utilizar un estándar laxo en la limitación de la libertad de expresión.
} 
enfoque es discutible, pues el estigma social derivado de una sanción puede depender más del ilícito cometido, o de la pena impuesta, que del tipo de norma en que esté consagrada. Además, en ciertos casos los efectos prácticos de las diversas normas sancionadoras serán similares ${ }^{105}$.

\section{d. Su eficacia}

Este es uno de los temas más importantes al momento de decidir si proscribir o no el hate speech. Quienes tienen una postura restrictiva sostienen que la penalización de la incitación al odio es un instrumento efectivo para combatirla. Ellos consideran que el hate speech puede ser atacado directamente a través de una ley, como sucede con muchos otros males que se enfrentan a través de su prohibición ${ }^{106}$; sin perjuicio de que la mayor o menor efectividad de una norma vendrá dada por los términos en los que esté formulada y el grado de compromiso que tengan los órganos encargados de ejecutarla.

Por el contrario, la postura liberal sostiene que la eficacia de este tipo de normas es, a lo menos, discutible ${ }^{107}$. Algunos sustentan esta afirmación con el ejemplo de la Sudáfrica del apartheid, cuyas normas contra la incitación al odio fueron usadas por décadas como instrumentos al servicio del poder dominante ${ }^{108}$. Otro caso es el de Alemania, que en los años previos al régimen Nacional Socialista tenía leyes contra el hate speech y las aplicaba debidamente ${ }^{109}$, pero estas mostraron ser ineficaces en el momento histórico en que fueron más necesarias. Incluso más, el nazismo habría usado los juicios seguidos por aplicación de leyes contra el hate speech como un medio para victimizar a los acusados, propagando así su mensaje ${ }^{110}$. En efecto, la prohibición del discurso de odio se basa en la premisa de que quienes escuchan el hate speech son suficientemente crédulos como para ser convencidos por tales expresiones, pero la misma proposición permitiría también afirmar que tales personas pueden ser influenciados por falsas teorías de conspiraciones gubernamentales en contra de los encarcelados por sus discursos de odio ${ }^{111}$.

Por lo anterior, algunos consideran que criminalizar el hate speech genera un efecto contrario al originalmente buscado, pues, en vez de silenciar a quienes profieren el discurso de odio, les entrega mayor publicidad y un cierto aura de mártir. Un ejemplo de esto es dado en la opinión disidente de la jueza MacLachlin en el caso Keegstra. Ella hace presente que Ernst Zundel, penado en una causa criminal relativa a expresiones racistas, afirmó que

$105 \mathrm{La}$ Corte Interamericana ha dispuesto que la aplicación de sanciones no criminales debe cumplir con los mismos requisitos que la imposición de penas penales, pues ambas serían manifestaciones del poder punitivo del Estado. Cfr. Baena Ricardo y Otros vs. Panamá (2001) párrs. 106 y 107.

106 Como sucede con todos los delitos prohibidos penalmente.

107 En este sentido, ver el estudio comparado de Sandra Coliver. Coliver (1992). Un par de sentencias que se refieren a este problema son los votos disidentes en $R$. vs. Keegstra (1990) p. 162 y Canadá (Human Rights Commission) vs. Taylor (1990) pp. 73 y 74.

108 En este sentido, ver Marcus (1992) y Johannessen (1992): “Should...”.

109 Las organizaciones judías de la época habrían compartido la noción del adecuado cumplimiento de estas normas, según Borovoy, A.A., When Freedoms Collide: The Case for Our Civil Liberties (1988) p. 50, citado por R. vs. Keegstra (1990) p. 162. Por el contrario, Coliver da un ejemplo de una ley alemana sobre injurias que no habría sido aplicada adecuadamente para proteger a los judíos. Coliver (1992) p. 365.

110 Ibid.

111 R. vs. Keegstra (1990) p. 162. Podrían afirmar que han sido encarcelados por “defender la verdad”. 
su condena le habría dado una publicidad que costaría un millón de dólares ${ }^{112}$. Algo similar podría afirmarse de David Irving, cuya fama se multiplicó exponencialmente desde su condena en Austria por el delito de negación del Holocausto.

Puede sostenerse que los argumentos recién descritos del enfoque liberal son discutibles. Por una parte, la inefectividad de leyes particulares que penalizaron la incitación al odio puede haberse debido a elementos propios de tales leyes, por ejemplo, los términos en que estaban redactadas. Por otra parte, el efecto intimidatorio de una ley de este tipo -siempre y cuando exista la voluntad política y social de que sea efectiva- evitará la promoción de la causa de los que odian, ya que estos se cuidarán de proferir tal tipo de expresiones. En efecto, si estas leyes no fuesen efectivas, la postura liberal no expresaría preocupación por su posible chilling effect.

Por su parte, la posición liberal frente al hate speech no pone en duda que una ley que penalice la incitación al odio sea efectiva para multar o encarcelar a quienes profieran ciertos discursos, sino que cuestiona que ella logre los efectos buscados por quienes la promulgan. En efecto, podría afirmarse que una ley de este tipo no impedirá que las personas más extremistas profieran su discurso, ya que estarán dispuestas a asumir las consecuencias de transmitir su mensaje. Ello haría que el resultado de una ley de este tipo fuera el peor posible: silenciaría a los moderados -quienes preferirían no hacer críticas que pueden ser adecuadas-, y daría la palma del martirio a los extremistas -dando una falsa importancia a sus argumentos-.

\section{e. Tolerancia}

La tolerancia es una figura que puede ser utilizada por ambos bandos en este debate sobre la penalización de la incitación al odio. Este uso en sentidos opuestos puede explicarse haciendo un contraste entre la virtud de la tolerancia y el principio de la tolerancia. Por una parte, la postura liberal hará uso de lo que llamaremos el principio de la tolerancia, considerado hoy en día uno de los pilares fundamentales de toda sociedad democrática $^{113}$. Según entiende este estudio, este es un principio prudencial que afirma que la autoridad debe tolerar ciertos males cuando de su represión se seguirían perjuicios mayores que los tolerados, o cuando de su tolerancia pueden derivarse bienes mayores que los que se seguirían de su represión, siempre y cuando dicha tolerancia no sea percibida como una aprobación del mal soportado ${ }^{114}$. Al aplicar este principio a la libertad de expresión, la autoridad tolerará discursos errados, de nulo valor social, desagradables o chocantes ${ }^{115}$, ya que si no lo hiciera, podría desaparecer el clima favorable búsqueda de la verdad. Lo anterior no impide limitar ciertos discursos, pero debe haber razones suficientemente graves que lo justifiquen.

\footnotetext{
112 R. vs. Keegstra (1990) pp. 160 y 161.

${ }^{113}$ Entre quienes enunciarían este principio se encuentran autores clásicos como el Aquinate (Cfr. De Aquino (S.D.) Parte I-II, cuestión 96), y modernos como Raz (1988) y Sandel (2002).

${ }^{114}$ Formulación reconstruida a partir de fuentes diversas.

115 Si la autoridad aceptara solo las expresiones bien recibidas, no estaría "tolerando" nada. Esto es sostenido por la Corte Europea de DD.HH., entre otras decisiones, en Handyside vs. Reino Unido (1976) párr. 49 y Otto-Preminger Institute vs. Austria (1994) párr. 49.
} 
La posición contraria, por su parte, considera que el principio de la tolerancia no es adecuado cuando las personas afectan el clima de respeto requerido por el orden público y la paz social. En tal situación, no sería el Estado el que debiera tolerar los discursos, sino que quienes profieren el hate speech son los que debieran tolerar a los que son diferentes. Esta postura afirma que el discurso de odio es una grave falta a la tolerancia, un insulto a quienes son distintos, por lo que debe ser prohibido por la autoridad. Así, la posición restrictiva no se basa en el principio de la tolerancia, sino que en la tolerancia de cada individuo hacia su prójimo, en aquella mezcla de respeto, paciencia y caridad necesaria para la vida en comunidad.

Es innegable que en gran medida la ley criminal sanciona actos contrarios a la moralidad. Sin embargo, no se puede pretender imponer la virtud a través de la ley penal, pues ella está destinada a sancionar faltas gravísimas ${ }^{116}$. Por ejemplo, no sancionará al mentiroso, sino al que, movido por sus vicios, cometa un fraude o algún acto de similar seriedad. Algo parecido debiera ocurrir en materia de hate speech: la ley penal no debe tratar de crear ciudadanos tolerantes, sino sancionar las faltas extremas contra dicha virtud democrática. De lo contrario se terminaría afectando el principio de la tolerancia, haciendo que la sociedad en su conjunto sea menos tolerante.

\section{CARACTERÍSTICAS RECOMENDABLES DE UNA PROHIBICIÓN DE LA INCITACIÓN AL ODIO}

Según se acaba de describir, la prohibición de la incitación al odio tiene pros y contras. Por ello, la promulgación de una ley de este tipo debe ser el fruto de una reflexión profunda sobre la conveniencia de su dictación, y sobre las características que se le dará. La siguiente sección busca proponer algunos requisitos mínimos que debiera cumplir una ley que prohíba la incitación al odio ${ }^{117}$. Al hacerlo, se tendrá en consideración cierta jurisprudencia comparada, principios jurídicos y políticas de incentivos. Por último, esta sección evaluará también la legislación nacional y el proyecto de ley actualmente en tramitación.

Uno de los requisitos que se proponen a continuación tendría el efecto de extender el alcance de una norma que penalice la incitación al odio, pues exigiría que la ley que sancione el hate speech sea de carácter general. Otros requisitos, como el establecimiento de un umbral de tolerancia y la exigencia de precisión, tendrían el efecto contrario. Con relación a estos últimos, debe hacerse presente que la limitación del alcance de una norma que sancione el hate speech no obsta a que la autoridad busque mecanismos no sancionatorios para enfrentar la incitación al odio, por ejemplo, el uso de políticas públicas de carácter educacional.

${ }^{116}$ La ley penal no puede imponer la virtud, aunque sí puede auxiliar a quienes la buscan.

117 Otros requisitos son enumerados en BerToni (2006) pp. 570-573. 


\subsection{LEy DE CARÁCTER GENERAL}

Toda norma que busque restringir la incitación al odio establecerá sanciones para quienes profieran este tipo de discursos. En muchas ocasiones tales penas serán de naturaleza criminal. Por ello, y por otros motivos que se detallarán, el primer requisito de una prohibición del hate speech será su establecimiento en una ley de carácter general. Dicho requisito exige:

a. Que la proscripción de la incitación conste en una ley, es decir, en una norma aprobada por el Congreso, no solo por el Poder Ejecutivo, y

b. Que la prohibición sea general, lo que significa que debe estar dirigida a proteger a todas las personas susceptibles de ser objeto de hate speech, no a grupos particulares.

El primer componente de este requisito deriva de la noción común de que toda restricción a una garantía fundamental debe ser establecida por una ley, entendida incluso en el sentido formal de la palabra ${ }^{118}$. Uno de los fines de este requisito es proteger de normas arbitrarias, a lo menos, a las mayorías. Esta exigencia es especialmente aplicable en el sistema jurídico chileno, pues la garantía constitucional de la libertad de emitir opinión y de informar sin censura previa dispone que los delitos cometidos en virtud de opiniones o informaciones deben ser establecidos en leyes de quórum calificado ${ }^{119}$. Lo anterior puede también desprenderse de la norma constitucional que establece cuáles son las materias de ley ${ }^{120}$.

El segundo componente de este requisito - la generalidad de la norma- busca proteger tanto a las mayorías como a las minorías, y no solo a las minorías influyentes, sino también a aquellas que no lo son. Un caso interesante en este sentido es R.A.V. vs. City of St. Paul ${ }^{121}$, en el que la Corte Suprema de Estados Unidos conoció de un recurso presentado por una persona condenada por quemar, junto a un grupo de jóvenes, una cruz hecha con palos de sillas que habían montado en el jardín cercado de una familia de raza negra $^{122}$. La norma que sirvió de base para la condena prohibía poner, en un lugar público o privado, un símbolo, objeto, graffiti, etc. -daba los ejemplos de una cruz en llamas y de una esvástica-, que pudiera provocar ira, alarma o resentimiento a personas "en virtud de su raza, color, credo, religión o género"123.

En este caso, la Corte Suprema no se pronunció sobre si la quema de cruces era o no una incitación al odio, sino que declaró que, incluso asumiendo que lo fuera, la citada

\footnotetext{
118 Sobre este requisito en el contexto de la Convención Americana de DD.HH., ver Medina y NASH (2007) pp. 32 y 33. Cfr. con la opinión consultiva de dicha Corte: La Expresión "Leyes” en el Artículo 30 de la Convención Americana sobre Derechos Humanos (1986) párr. 27.

119 Art. $9^{\circ} \mathrm{N}^{\circ} 12$ de la Constitución Política de la República. Decreto Nº 100 (2005).

120 Art. 63 números 2, 3 y 20 de la Constitución Política de la República. Decreto Nº 100 (2005).

121 R.A.V. vs. City of St. Paul (1992).

${ }^{122}$ La quema de cruces, ligada al Ku Klux Klan, es una acción cuyo elemento expresivo supera con creces la mera acción de quemar un par de maderos. Otro caso de quema de cruces es Virginia vs. Black (2003).

123 Bias-Motivated Crime Ordinance, St. Paul, Minn. Legis. Code, Art. 292.02 (1990), citada por R.A.V. vs. City of St. Paul (1992) p. 380.
} 
norma era inconstitucional, pues criminalizaba expresiones que ofendieran a las personas en virtud de ciertas condiciones particulares (raza, color, credo, religión o género), privilegiando tales características por sobre las demás. En otras palabras, esta norma permitiría proferir discursos de odio en contra de personas que se encontraran en condiciones no protegidas, por ejemplo, afiliación política, sindical o discapacidad. Así, se podría castigar a quien dijera "todos los católicos son unos malnacidos", pero no a quien dijera "todos los anticatólicos son unos malnacidos", inclinando la balanza en favor de un grupo. La parte recurrida alegó que esta diferenciación no era arbitraria, pues buscaba proteger a grupos históricamente afectados por discriminaciones. Sin embargo, la Corte consideró que esa excusa no era suficiente como para que el mismo Estado empezara, a su vez, a discriminar según puntos de vista (viewpoint discrimination) ${ }^{124}$.

Una norma como la descrita puede conseguir una cierta aplicación general, pero solo dentro de categorías determinadas; por ejemplo, en el caso de la religión, protegerá tanto a judíos como a cristianos. Sin embargo, una normativa que apunte solo a algunas condiciones específicas, desconoce que las consecuencias para los afectados por el hate speech -sean estos de alguna minoría religiosa, discapacitados, etc.- pueden ser similares, con independencia del motivo en que se base la incitación ${ }^{125}$. En efecto, la gravedad de este discurso puede depender más del contenido de las palabras, que de la categoría por la cual se profiere, por lo que el requisito impuesto por la Corte Suprema de Estados Unidos parece razonable. Esto es especialmente cierto porque toda enumeración de grupos discriminados - por muy amplia que sea la lista- excluirá a otros que igualmente requieran de protección legal. Por ello, conviene que estas normas sean abiertas ${ }^{126}$.

Lamentablemente el enfoque de la Corte Suprema de Estados Unidos no es mayoritario, pues generalmente las leyes contra el hate speech buscan proteger a ciertas categorías determinadas ${ }^{127}$. Alemania adopta una postura mixta, ya que castiga a quienes incitan al odio o atacan la dignidad, etc., de "partes de la población", sin hacer especificaciones ${ }^{128}$, pero también, cuenta con normas más particulares, como aquella que sanciona la negación del Holocausto, acto que es entendido como una forma particular de incitación al odio.

En el ámbito nacional, la norma existente sobre incitación al odio, y el proyecto de ley actualmente en tramitación, cumplen con la característica de ser presentados en la forma de una ley. Sin embargo, ninguna de estas es general, ya que prohíben la promoción del odio u hostilidad solo en contra de grupos determinados, dejando afuera categorías como la clase social, relacionada con varios discursos de odio en nuestro país. Ello es criticable, y por eso Manuel de Rivacoba planteó, durante la discusión del antiguo proyecto de ley sobre discriminación racial y étnica, que una norma contraria a la discriminación debía ser lo más genérica y amplia posible, puesto que en el futuro podrían aparecer nuevas

${ }^{124}$ R.A.V. vs. City of St. Paul (1992) p. 391. Sobre la protección de la igualdad y la libertad, en relación con la discriminación según punto de vista, ver Fiss (1995) pp. 285-291.

125 R.A.V. vs. City of St. Paul (1992), pp. 391-392.

126 Esto es muy bien reflejado en Lynch (1999) pp. 620 ss.

127 V. gr. Racial and Religious Hatred Act (2006).

128 Norma citada en Brugger (2002) p. 5. 
formas de discriminación ${ }^{129}$. Los hechos mostrarían que dicho argumento fue adecuado, ya que el conocido eslogan "pitéate un flaite" no podría haber sido perseguido a través de la normativa vigente en materia de incitación al odio, y probablemente por eso fue enfrentado mediante la interposición de un genérico recurso de protección ${ }^{130}$.

\subsection{Precisa}

La Corte Interamericana de Derechos Humanos sostiene que la delimitación estricta y unívoca de las conductas delictivas es un elemento integrante del principio de legalidad, establecido en el artículo 9 del Pacto de San José. Este es aplicable no solo a disposiciones penales, sino que a toda manifestación de la potestad punitiva del Estado ${ }^{131}$. Tal principio "implica una clara definición de la conducta incriminada, que fije sus elementos y permita deslindarla de comportamientos no punibles o conductas ilícitas sancionables con medidas no penales" 132 .

En general, el requisito enunciado por la Corte Interamericana deriva del principio penal básico nullum crimen, nulla poena sine lege penali, praevia, stricta et scripta, que, entre otras cosas, requiere que las normas sancionatorias estén establecidas en forma previa y precisa, de modo que las personas puedan pronosticar las consecuencias de sus acciones. Una norma que no delimite en forma precisa los tipos de incitación al odio que busca prohibir, terminará abarcando muchas expresiones que el legislador no habría buscado sancionar. Esta falta de definición puede ser enfrentada por la autoridad de diversos modos. Uno de ellos sería que la norma no fuese aplicada, con la consecuencia de que no se sabría si la conducta debe realmente evitarse. Otro modo, aún peor que el anterior, sería que dicha norma fuese aplicada selectivamente, de modo que el discurso fuese o no perseguido, según su conformidad con el ideario del gobernante.

Además, si una ley de hate speech no es acotada, será la judicatura la encargada de delimitar sus efectos, definiendo el sentido jurídico y alcance de los términos utilizados. Esta labor no solo es difícil ${ }^{133}$, sino que implica determinar qué acciones son penalizadas -por ejemplo, si se excluye la exhibición de ciertas expresiones artísticas-, lo que contraría el principio de que las conductas punibles deben estar establecidas en la ley, no en la práctica judicial ${ }^{134}$. Lamentablemente, no es sencillo acotar legalmente una norma que prohíba la incitación al odio, ya que la misma palabra "odio" es muy imprecisa, pues significa: "Antipatía y aversión hacia algo o hacia alguien cuyo mal se desea"135. Así, por ejemplo, denunciar la corrupción de un Gobierno producirá una "antipatía” hacia este y un deseo de su salida del poder - un mal para los gobernantes-, pero esa denuncia no es una acción

\footnotetext{
129 Comisión de DD.HH., Nacionalidad y Ciudadanía de la Cámara de Diputados (2005) p. 20.

130 Después de presentado el recurso, este eslogan fue sacado del aire de forma inmediata y voluntaria.

131 Baena Ricardo y Otros vs. Panamá (2001) párrs. 106 y 107.

132 Castillo Petruzzi vs. Perú (1999) párr. 121.

133 Por ejemplo, la Corte Constitucional húngara señala que la jurisprudencia había acotado a través de cien años lo que era la incitación al odio. Caso 12/1999(1999) II 3.2.

${ }^{134}$ El sistema de precedentes puede lograr un efecto similar al conseguido por las leyes precisas, pero ello no sucede en ordenamientos de corte legalista en que los jueces se consideran totalmente autónomos al interpretar las leyes.

135 Diccionario de la R.A.E., citado en Ministerio Público de Villa Alemana contra Quijada Avilés (2010) p. 47.
} 
reprochable. Por ello, convendría desterrar la palabra "odio" de las tipificaciones del hate speech, reemplazándola por conceptos más cuantificables -como el llamado a cometer crímenes-, o establecer una definición legal de dicho término ${ }^{136}$.

Son varios los fallos y opiniones referidos a la necesidad de que una ley sea precisa. En Beauharnais vs. People of the State of Illinois (1952), una de las razones para aceptar una cierta prohibición del discurso de odio fue que la norma no era una catchall enactment, es decir, una norma según la cual cualquier expresión podría ser incluida y penada a discreción de la autoridad. Otro ejemplo es el caso de Faurisson vs. Francia (1993), seguido ante el Comité de Derechos Humanos de las Naciones Unidas, donde el recurrente alegaba que el Estado estaba afectando su libertad de expresión al aplicarle una ley que criminalizaba, entre otros actos, la negación del Holocausto ${ }^{137}$. En su sentencia, el Comité de Derechos Humanos hizo presente que en el caso analizado no se había violado la libertad de expresión, pero que la amplitud de la norma podría afectar tal garantía en casos posteriores. Esto fue afirmado con especial fuerza por los votos concurrentes de algunos integrantes del Comité, como el de la chilena Cecilia Medina ${ }^{138}$.

Con relación a las leyes nacionales, la falta de precisión fue uno de los motivos por los cuales el concepto "menosprecio", existente en la antigua Ley sobre Abusos de Publicidad, no se mantuvo en la Ley sobre Libertades de Opinión e Información y Ejercicio del Periodismo ${ }^{139}$. Sin embargo, la exclusión de esa palabra no es suficiente para dar precisión a las normas vigentes en Chile, pues, por ejemplo, el odio podría incitarse a través de la simple crítica de las prácticas de los miembros de una determinada religión. El proyecto de ley en trámite sufre de la misma falta de precisión. Hasta el momento no se han dado interpretaciones erradas a la normativa vigente, pero el que una norma no haya sido mal utilizada no significa que no pueda serlo. Atendido que un modo de acotar las normas de hate speech es a través del establecimiento de un claro umbral de tolerancia, cuestión que se trata más adelante, no se ahondará más en este punto.

\subsection{Adecuada, NECESARIA y PROPORCIONAL}

El conflicto existente entre la libertad de expresión y otros bienes jurídicos, hace necesario que el legislador tome una posición para solucionarlo ${ }^{140}$. Al hacerlo, deberá ponderar la legitimidad y conveniencia de restringir las distintas garantías fundamentales. Una forma de hacer esta ponderación es mediante un estudio de proporcionalidad, como hacen muchos tribunales al pronunciarse sobre la constitucionalidad de leyes que restringen garantías fundamentales no absolutas. Algunos de dichos tribunales se consideran, incluso, obligados a hacer este estudio, como sucede cuando las constituciones políticas establecen que los derechos fundamentales pueden ser restringidos solo en la medida en que tales li-

\footnotetext{
136 Por ejemplo, la ley de la República de Irlanda hace esto. Prohibition of Incitement to Hatred Act (1989), sección 1(1). Sin embargo, su definición resulta ser circular, pues dispone que odio significa "odio en contra de...". Ibid.

137 Loi Tendant à Réprimer Tout Acte Raciste, Antisémite ou Xénophobe (1990).

138 Otro ejemplo es el voto disidente del juicio Canadá (Human Rights Commission) vs. Taylor (1990).

139 Biblioteca del Congreso Nacional de Chile (2001) pp. 417, 418 y 1146.

${ }^{140}$ Este estudio no entrará en la discusión de si estos conflictos son reales o aparentes.
} 
mitaciones sean necesarias en una sociedad democrática ${ }^{141}$, pues algunos tribunales traducen este requisito como un mandato de efectuar un estudio de proporcionalidad ${ }^{142}$.

Sin embargo, aunque no exista obligación de efectuar este análisis, puede ser conveniente hacerlo, ya que proporciona un modo estructurado para determinar si existe una causa justificada para restringir un derecho no absoluto. Los estudios de proporcionalidad son generalmente llevados adelante por tribunales encargados del control de constitucionalidad de las leyes, pero ello no obsta a que sean también utilizados por órganos legislativos. Es más, resulta conveniente que tanto estos como los tribunales utilicen procesos similares para razonar sobre la constitucionalidad de las leyes.

El estudio de proporcionalidad analiza, generalmente, tres factores en la disposición que busca limitar una garantía fundamental: a. Si es adecuada (debe ser capaz de lograr el objetivo propuesto); b. Si es necesaria (debe ser la menos restrictiva para lograr el fin deseado), y c. Si es proporcional en sentido estricto (debe haber un equilibro entre la medida restrictiva y el objetivo propuesto) ${ }^{143}$. En materia de hate speech, un ejemplo de un cierto análisis de los requisitos del estudio de proporcionalidad, pero sin el orden que lo caracteriza, puede verse en el voto concurrente de Evatt y Kretzmer, en el fallo ya citado de Faurisson vs. Francia (1993). En este se analiza el poder establecido en el Pacto Internacional de Derechos Civiles y Políticos para limitar la libertad de expresión ${ }^{144}$.

Este voto concurrente afirma que, para limitar una expresión, no basta con que se afecte la reputación de los demás, la seguridad nacional, el orden público, la salud pública o la moral, sino que es necesario que la medida sea proporcional. Sostiene que debe haber una relación adecuada entre la restricción impuesta a la libertad de expresión y el bien que se siga de dicha limitación. Asimismo, afirma que la restricción no debe ser mayor a la estrictamente necesaria para proteger este valor, ni puede poner en peligro el derecho mismo a la libertad de expresión. Finalmente, concluye que el propósito de la prohibición establecida en la Ley Gayssot -aquella en virtud de la cual se condenó a Faurisson- se podría haber cumplido sin una norma tan drástica. No obstante ello, consideró que la sanción fue proporcionada en el caso particular del demandante ${ }^{145}$.

Si el legislador utilizara el estudio de proporcionalidad como indicador de la constitucionalidad de la norma que se busca promulgar, serán varios los factores que pueden ser tenidos en consideración, especialmente al analizar su tercer componente (la proporcionalidad en sentido estricto). Algunos de estos serán:

a. La relación entre los bienes que efectivamente se deriven de la restricción de la libertad de expresión, y el mal que representa esta limitación en sí misma;

\footnotetext{
141 V. gr. Canadian Charter of Rights and Freedoms; Convenio Europeo para la Protección de los Derechos Humanos y de las Libertades Fundamentales (1950), y leyes domésticas que se remiten a dicha Convención, como la Human Rights Act (1998) británica.

142 V. gr. los casos canadienses y de la Corte Europea de Derechos Humanos referidos a lo largo de este artículo. Las sentencias húngaras citadas también hacen referencia a estudios de proporcionalidad.

143 Sottiaux y Van Der SChyff (2008) p. 130.

144 Tercer párrafo del artículo 19. Este voto concurrente es también firmado por Klein.

145 Faurisson vs. Francia (1993) párrs. 8-10 del voto concurrente de Evatt y Kretzmer, también firmado por Klein.
} 
b. El efecto intimidatorio que una restricción a la libertad de expresión puede tener sobre los discursos de cierto valor, el que dependerá de la amplitud de la norma que regule el hate speech;

c. La relevancia social de la expresión afectada, por ejemplo, si afecta al periodis$\mathrm{mo}^{146}$;

d. La historia del país que restringe la expresión; por ejemplo, el pasado comunista de Hungría le hace favorecer la libertad de expresión, y en Alemania, la memoria viva del Holocausto le hace tomar una posición restrictiva del hate speech, y

e. El texto constitucional que declara la garantía fundamental a la expresión y a los demás derechos que puedan verse afectados por su abuso ${ }^{147}$.

Ninguno de los factores enumerados será determinante por sí mismo. Por ejemplo, a pesar de que Sudáfrica tiene una historia marcada por la discriminación, y disposiciones constitucionales claras contra la incitación al odio, se ha considerado que ciertas limitaciones a la libertad de expresión -aceptadas en otras jurisdicciones- no son suficientemente proporcionadas ${ }^{148}$. Sin embargo, esto puede también deberse a un motivo histórico opuesto: el recuerdo de varias décadas de mal uso de normas contra la incitación al odio por parte de la minoría dominante ${ }^{149}$.

El estudio de proporcionalidad no es el único modo de enfrentar el conflicto que puede existir entre dos derechos. Sin embargo, tiene la ventaja de ser sistemático, por lo que parece recomendable para Chile. En efecto, este estudio incentivaría un análisis más profundo sobre cuándo y en qué forma es posible restringir la libertad de expresión, temas que no fueron considerados detalladamente en la discusión parlamentaria sobre la criminalización del hate speech.

\subsection{Prever cierto umbral de tolerancia}

No toda incitación al odio es igualmente dañosa. Algunas pueden no afectar ninguno de los bienes jurídicos protegidos con la criminalización del hate speech. Ello sucedería, por ejemplo, al incitar al odio, en privado, a una persona muy bien dispuesta en favor de la minoría objeto del discurso. Algo similar sucede con las amenazas, otro delito cometido mediante expresiones. Es por ello que nuestro ordenamiento sanciona solo las amenazas hechas seriamente, y siempre que de los antecedentes aparezca verosímil la consumación del acto ${ }^{150}$. En otras palabras, las amenazas se penalizan solo cuando las circunstancias de las mismas lo ameritan. Además, no todas tienen la misma sanción. Esto debiera tenerse presente al considerar la penalización de la incitación al odio, especialmente, porque muchas veces las amenazas pueden alterar en forma más seria que el hate speech la vida de la víctima.

\footnotetext{
146 Ver Jerslid vs. Dinamarca (1994). Cfr. Ivanov vs. Rusia (2007).

147 En Chile, "[l]a libertad de opinión fue (...) concebida como la más amplia de las libertades intelectuales". Cea Egaña (1981) p. 8.

148 Ver The Islamic Unity Convention vs. The Independent Broadcasting Authority (2002).

${ }^{149}$ Ver Marcus (1992), Johannessen (1992): “Should...” y Coliver (1992) p. 372.

150 Art. 296 del Código Penal.
} 
Existen críticas políticas o sociales que pueden revestir características de hate speech. Por eso, si se tratara de acabar del todo con la incitación al odio, se terminaría afectando la opinión, cayendo en la trampa del summum ius summa iniuria. Además, si un Estado pretendiera criminalizar todo hate speech, probablemente no actuaría con una coherencia modelo, según puede observarse en países con un enfoque muy restrictivo. Por ejemplo, Alemania es, en algunos casos, muy quisquillosa para determinar qué constituye una incitación al odio ${ }^{151}$, mientras que en otros no lo es tanto ${ }^{152}$. Esta diferencia puede reflejar la popularidad de las ideas expresadas, constituyendo una discriminación arbitraria. Por lo anterior, una norma que sea realista en su prohibición de la incitación al odio establecerá un cierto nivel de tolerancia frente esta.

En este punto, conviene referirse a una decisión de la Corte Constitucional húngara, recaída en un caso de control preventivo de constitucionalidad de un proyecto de ley que buscaba reformar la norma penal sobre incitación al odio ${ }^{153}$. Entre las modificaciones de tal proyecto se encontraba el reemplazo de la expresión vigente "incitar al odio" por la de "provocar odio", conceptos a los que la jurisprudencia húngara había otorgado alcances diversos ${ }^{154}$. Mientras el incitador debía buscar que las masas hicieran algo negativo, el provocador solo buscaría influir en el modo de pensar de los oyentes mediante argumentos racionales y de persuasión ${ }^{155}$. La Corte determinó que prohibir la provocación de odio reduciría la libertad de expresión a un nivel incompatible con el derecho constitucional respectivo, cuyas restricciones se permiten solo cuando las expresiones atentan gravemente contra otras garantías fundamentales.

De este modo, para limitar expresiones de hate speech en Hungría, no basta con que ellas afecten hipotéticamente la paz social, sino que debe existir un peligro claro y actual en contra de otros derechos fundamentales. La Corte dejó sentado que, así como muchas veces las palabras ofensivas no alcanzan el umbral de gravedad requerido para ser sancionadas como injurias o calumnias, existen discursos de odio que no son suficientemente graves como para ser castigados penalmente. El umbral requerido en Hungría para coartar la libertad de expresión respecto del hate speech, exige que la incitación apele directamente a una acción violenta. Este enfoque es más moderado que el estándar de Brandenburg.

Una de las consideraciones de la Corte para arribar al resultado anterior, es que criminalizar el llamado a cometer una acción violenta sería similar a condenar un mero acto preparatorio, cuestión excesiva si se consideran los efectos de esta penalización en la libertad de expresión, como el efecto inhibitorio de expresiones valiosas. Además, esta criminalización se realiza con independencia de la respuesta que se obtenga de parte de

\footnotetext{
${ }^{151}$ Como al condenar a quienes cuestionan la magnitud de ciertos hechos históricos. Ver BRUGGER (2002) p. 15 .

152 Caso Los Soldados son Asesinos (1995), en Schwabe (2009) pp. 219 ss.

153 Caso 18/2004 (2004). La norma que se buscaba reformar era el Art. 269 del Código Penal, artículo que se hallaba redactado en términos aceptables para la Corte.

${ }^{154}$ En castellano ambos conceptos pueden ser considerados sinónimos, pero eso no es así en otros idiomas, v. gr. los conceptos ingleses incitement y provocation tienen una connotación diversa.

155 Caso 18/2004 (2004) III, 3.2.
} 
los oyentes, lo que la torna aún más compleja. El fallo citado también enfatiza que existen muchos modos de proteger los derechos afectados por el hate speech, y que el derecho penal debe ser usado solo cuando la violación sea de suma gravedad.

En la legislación nacional vigente se contempla un umbral de tolerancia determinado por el medio a través del cual se realiza el hate speech-si es o no de comunicación social-, pero que nada sostiene sobre si el discurso hace o no un llamado a la violencia. El proyecto de ley en tramitación ni siquiera establece un umbral. A nuestro entender, es más adecuado que el umbral de tolerancia se refiera al contenido de la expresión, de modo que prohíba solo expresiones particularmente graves. Ello disminuiría el chilling effect que podría producir una norma sobre incitación al odio. En este sentido, el umbral de tolerancia vigente -dependiente del medio de comunicación a través del cual se efectúa el hate speech- no es adecuado para prevenir el efecto intimidatorio de ciertas expresiones de importancia social, ya que muchas de ellas, como las periodísticas, se efectuarán mayoritariamente a través de medios de comunicación social. Por ello, parecería adecuado exigir un umbral de tolerancia por contenido, intermedio entre el de Estados Unidos -que puede ser ineficaz contra los llamados a la violencia con efectos no inmediatos, pero seguros- y el de la posición restrictiva. Este umbral intermedio prohibiría hacer llamados serios a la violencia física ilegal, ya sea que estos utilicen un lenguaje directo o figurado ${ }^{156}$. El umbral de tolerancia propuesto se refiere solo a las expresiones de incitación al odio, ya que si se afecta otro bien jurídico, el umbral será probablemente distinto, dependiendo del análisis que se haga sobre el particular.

\section{CONCLUSIÓN}

Las sociedades tienen distintos niveles de tolerancia frente al discurso que abusa de la libertad de expresión. Estos dependerán de diversos factores, como la naturaleza del bien jurídico afectado, las condiciones subjetivas de la audiencia, la mayor o menor publicidad de la expresión, las condiciones sociales del Estado donde se profiere, etc. Este estudio expuso dos visiones contrarias sobre el modo de enfrentar un discurso específico, el de incitación al odio. Tales perspectivas fueron clasificadas, a grandes rasgos, como posiciones liberal y restrictiva, para ser luego descritas y ejemplificadas mediante la exposición de jurisprudencia extranjera. Posteriormente, después de una rápida consideración sobre los efectos negativos del hate speech, este estudio revisó algunos motivos a favor y en contra de su prohibición. Finalmente, señaló cuáles serían los requisitos que debiera tener una norma que prohíba la incitación al odio para ser adecuada, a saber: estar establecida en una ley de carácter general; ser precisa, adecuada, necesaria y proporcional, y contener un cierto umbral de tolerancia.

Este trabajo también estudió la situación actual de Chile, analizando el único y reciente caso en el que un tribunal aplicó la normativa vigente. En nuestro país, a pesar de

\footnotetext{
156 Knechtle propone usar el estándar de "amenazas verdaderas" (true threats). Knechtle (2006) pp. 569 ss. Al exigir que el llamado a la violencia sea "ilegal”, se excluyen los llamados a la violencia legítima, como sería el caso de un encarcelamiento previo juicio justo.
} 
existir una norma sobre incitación al odio y un proyecto de ley relevante en tramitación, no ha habido suficiente discusión sobre el tema del hate speech. Al hacer tal análisis, este artículo puso de relieve que la legislación vigente y el proyecto en discusión no cumplen con varios de los requisitos que este estudio propone. Por ejemplo, el proyecto en discusión solo regirá para ciertos grupos determinados, por lo que dejará afuera posibles incitaciones. Además, no requiere que el discurso sobrepase un umbral de tolerancia para ser penado, lo que puede tener un nocivo efecto inhibitorio de la expresión. Por ello, convendría que se reformara la normativa actual y el proyecto de ley en tramitación, particularmente este último.

El derecho a la libertad de expresión es fundamental para el adecuado funcionamiento de una sociedad democrática y para el desarrollo individual de sus miembros. Por ello, y por las constantes amenazas de que es objeto, este derecho es generalmente garantizado en documentos de rango constitucional. Ellos buscan proteger la expresión, especialmente, cuando esta pueda chocar con las "verdades oficiales" o socialmente aceptadas, pues será justamente entonces cuando las mayorías o el poder gobernante tratarán de reprimirla. Dentro de estas expresiones se halla la indeseada incitación al odio, que en algunos casos puede, o debe, ser limitada. Sin embargo, no se debe olvidar que las restricciones inadecuadas del hate speech son capaces de afectar expresiones valiosas -políticas, artísticas o de otra índole- que podrían caber dentro de definiciones amplias de incitación al odio.

\section{BIBLIOGRAFÍA}

Bellacosa, Joseph W. (1993): “The Regulation of Hate Speech by Academe vs. The Idea of a University: A Classic Oxymoron?”, St. John's Law Review, № 67 (1): pp. 1-12.

Bertoni, Eduardo Andrés (2006): "Hate Speech Under the American Convention on Human Rights", ILSA Journal of International and Comparative Law, № 12: pp. 569574.

Biblioteca del Congreso Nacional de Chile (2001): Historia de la Ley $N^{\circ} 19.733$ Sobre Libertades de Opinión e Información y Ejercicio del Periodismo, 1475 pp. Disponible en: <http://www.bcn.cl/obtienearchivo?id=recursoslegales/10221.3/2428/1/ HL19733.pdf> [fecha de consulta: 25 de octubre de 2010].

Brugger, Winfried (2002): "Ban on or Protection of Hate Speech? Some Observations Based on German and American Law", Tulane European \& Civil Law Forum, № 17: pp. 1-21.

Carnevalli Rodríguez, Raúl (2008): "Derecho Penal como Ultima Ratio. Hacia una Política Criminal Racional”, Revista Ius et Praxis, Vol. 14, Nº 1: pp. 13-48.

Cea Egaña, José Luis (1981): "Estatuto Constitucional de la Información y Opinión”, Revista Chilena de Derecho, Vol. 8: pp. 5-40.

Cisternas Reyes, María Soledad (2004): "Ordenamiento Jurídico Chileno Frente al Fenómeno Discriminatorio”, Revista Chilena de Derecho, Vol. 31: pp. 409-437.

Coliver, Sandra (1992): "Hate Speech Laws: Do They Work?", en: Coliver, Sandra (Ed.) (1992) pp. 363-374. 
Coliver, Sandra (Ed.) (1992), Striking a Balance: Hate Speech, Freedom of Expression and Non-discrimination (Londres-Essex, Article 19-International Centre against Censorship, Human Rights Centre-University of Essex) 417 pp.

Comisión de DD.HH., Nacionalidad y Ciudadanía de la Cámara de Diputados (2005), "Primer Informe de la Comisión de Derechos Humanos, Nacionalidad y Ciudadanía Recaído en el Proyecto que Establece Medidas Contra la Discriminación” (18 de mayo) 51 pp.

Comisión de DD.HH., Nacionalidad y Ciudadanía del Senado (2008), "Informe Complementario del Segundo Informe de la Comisión de Derechos Humanos, Nacionalidad y Ciudadanía, Recaído en el Proyecto que Establece Medidas Contra la Discriminación" (3 de junio) 46 pp.

De Aquino, Santo Tomás (S.D.): Suma Teológica. Disponible en: <http://hjg.com.ar/ sumat/index.html> [fecha de consulta: 25 de octubre de 2010].

Errera, Roger (1992): "In Defence of Civility: Racial Incitement and Group Libel in French Law”, en: Coliver, Sandra (Ed.) (1992) pp. 144-158.

Faúndez Ledesma, Héctor (2004): Los Limites de la Libertad de Expresión (México D.F., Universidad Nacional Autónoma de México, Instituto de Investigaciones Jurídicas) $782 \mathrm{pp}$.

Fernández González, Miguel Ángel (2001): “Libertad de Expresión, Censura Previa y Protección Preventiva de los Derechos Fundamentales", Revista Chilena de Derecho, Vol. 28: pp. 383-400.

Fiss, Owen M. (1995), “The Supreme Court and the Problem of Hate Speech”, Capital University Law Review, No 24: pp. 281-291.

Houser, Justin Kirk (2009), "Is Hate Speech Becoming the New Blasphemy? Lessons from an American Constitutional Dialectic", Pennsylvania State Law Review, No 112: pp. 571-619.

Johannessen, Lene (1992): “Denmark: Racist Snakes in the Danish Paradise", en: Coliver, Sandra (Ed.) (1992) pp. 140-143.

Johannessen, Lene (1992): "Should Censorship of Racist Publications Have a Place in the New South Africa?”, en: Coliver, Sandra (Ed.) (1992) pp. 223-237.

Knechtle, John C. (2006): "When to Regulate Hate Speech", Pennsylvania State Law Review, $\mathrm{N}^{\circ}$ 110: pp. 539-578.

LynCH, Brendan P. (I999): "Personal Injuries or Petty Complaints?: Evaluating the Case for Campus Hate Speech Codes: The Argument from Experience", Suffolk University Law Review, No 32: pp. 613-646.

Marcus, Gilbert J (1992): "Racial Hostility: The South African Experience", en: Coliver, Sandra (Ed.) (1992) pp. 208-222.

Medina Quiroga, Cecilia y Nash Rojas, Claudio (2007): Sistema Interamericano de Derechos Humanos: Introducción a sus Mecanismos de Protección (Santiago, Universidad de Chile. Facultad de Derecho. Centro de Derechos Humanos) 229 pp.

Nogueira Alcalá, Humberto (2000): “El Derecho a la Información en el Ámbito del Derecho Constitucional Chileno y Comparado en Iberoamérica y Estados Unidos", Revista Ius et Praxis, Vol. 6, N 1: pp. 321-404. 
Nota (1993): "Hate Is Not Speech: A Constitutional Defense of Penalty Enhancement for Hate Crimes", Harvard Law Review, N 106: pp. 1314-1331.

Nota (1993): "The Demise of the Chaplinsky Fighting Words Doctrine: an Argument for its Interment”, Harvard Law Review, N 106: pp. 1129-1146.

Pasqualucci, Jo M. (2006): "Criminal Defamation and the Evolution of the Doctrine of Freedom of Expression in International Law: Comparative Jurisprudence of the InterAmerican Court of Human Rights", Vanderbilt Journal of Transnational Law, $\mathrm{N}^{\circ} 39$ : pp. 379-433.

Politoff, Sergio (1999): "Informe sobre los Delitos de Discriminación en el Derecho Penal Comparado. (A la Luz del Proyecto de Ley sobre Discriminación Racial y Étnica (Boletín No 2142-17))", Revista Ius et Praxis, Vol. 5, No 2: pp. 193-213.

Raz, Joseph (1988): "Autonomy, Toleration and the Harm Principle", en: Mendus, Susan (Ed.), Justifying Toleration: Conceptual and Historical Perspectives (Cambridge, Cambridge University Press) pp. 155-175.

Redish, Martin H. (1982): "Advocacy of Unlawful Conduct and the First Amendment: In Defense of Clear and Present Danger", California Law Review, Vol. 70, N 5: pp. 1159-1200.

Ribera Neumann, Teodoro (1985): “Alcances y Finalidad del Artículo $8^{\circ}$ de la Constitución Política del 80”, Estudios Públicos, N²0: pp. 253-289.

SAndel, Michael J. (2002): "Judgemental Toleration", en: George, Robert P. (Ed.), Natural Law, Liberalism and Morality (New York, Oxford University Press) pp. 107112.

Schabas, William A. (2000): "Hate Speech in Rwanda: The Road to Genocide", McGill Law Journal / Revue de Droit de McGill, No 46: pp. 141-171.

Schwabe, Jürgen (2009): Jurisprudencia del Tribunal Constitucional Federal Alemán: Extractos de las Sentencias más Relevantes Compiladas por Jürgen Schwabe (Traducc. Marcela Anzola Gil y Emilio Maus Ratz, Berlín - México D.F., Konrad Adenauer Stiftung) 669 pp.

Sottiaux, Stefan y Van der Schyff, Gerhard (2008): "Methods of International Human Rights Adjudication: Towards a More Structured Decision-Making Process for the European Court of Human Rights", Hastings International and Comparative Law Review, No 31: pp. 115-156.

\section{JURISPRUDENCIA CITADA}

Baena Ricardo y Otros vs. Panamá (2001): Corte Interamericana de DD.HH., Serie C Nº 72.

Beauharnais vs. People State of Illinois (1952): Corte Suprema de EE.UU., 343 U.S. 250.

Brandenburg vs. Ohio (1969): Corte Suprema de EE.UU., 395 U.S. 444.

Canadá (Human Rights Commission) vs. Taylor (1990): Corte Suprema de Canadá, 3 S.C.R. 892.

Caso 12/1999 (1999): Corte Constitucional de Hungría (versión inglesa).

Caso 18/2004 (2004): Corte Constitucional de Hungría (versión inglesa). 
Castillo Petruzzi vs. Perú (1999): Corte Interamericana de DD.HH., Serie C Nº 52. Chaplinsky vs. New Hampshire (1942): Corte Suprema de EE.UU., 315 U.S. 568. Collin vs. Smith (1978): Corte de Apelaciones, Seventh Circuit (EE.UU.), 578 F. 2d 1197. Faurisson vs. Francia (1993): Comité de DD.HH. (ONU), CCPR/C/58/D/550/1993. García Valdés y Otros con Consejo de Calificación Cinematográfica (1997): Corte Suprema de Chile, 20 de enero (apelación de recurso de protección), Fallos del Mes, N ${ }^{\circ} 463$ (1997), pp. 824-843.

Handyside vs. Reino Unido (1976): Corte Europea de DD.HH., Acción No 5493/72. Herrera Ulloa vs. Costa Rica (2004): Corte Interamericana de DD.HH., Serie C Nº 107. Ivanov vs. Rusia (2007): Corte Europea de DD.HH., Acción No 35222/04. Jerslid vs. Dinamarca (1994): Corte Europea de DD.HH., Acción N 15890/89. Kimel vs. Argentina (2008): Corte Interamericana de DD.HH., Serie C No 177. La Expresión "Leyes» en el Artículo 30 de la Convención Americana sobre Derechos Humanos (1986): Corte Interamericana de DD.HH., Opinión Consultiva OC-6/86, Serie A No 6. Lehideux e Isorni vs. Francia (1998): Corte Europea de DD.HH., Acción No 24662/94. Los Soldados son Asesinos (traducción) (1995): Tribunal Constitucional Federal Alemán, Primera Sala, 93, 266, en Schwabe (2009) p. 219-226.

Miller vs. California (1973): Corte Suprema de EE.UU., 413 U.S. 15.

Ministerio Público de Villa Alemana contra Quijada Avilés (2010): Tribunal de Juicio Oral en lo Penal de Viña del Mar, 15 y 16 de junio (juicio oral en lo penal en causa sobre otras faltas y delitos de la ley 19.733, y otros delitos), RUC Nº 0901108439-4 y RIT $\mathrm{N}^{\circ} 127-2010$.

Olmedo Bustos y Otros vs. Chile (La Última Tentación de Cristo) (2001): Corte Interamericana de DD.HH., Serie C Nº 73.

Otto-Preminger Institute vs. Austria (1994): Corte Europea de DD.HH., Acción No $13470 / 87$.

R. vs. Keegstra (1990): Corte Suprema de Canadá, 3 S.C.R. 697.

R. vs. Zundel (1992): Corte Suprema de Canadá, 2 S.C.R. 731.

R.A.V. vs. City of St. Paul, Minesota (1992): Corte Suprema de EE.UU., 505 U.S. 377.

Rice vs. Paladin Enterprises (1997): Corte de Apelaciones, Fourth Circuit (EE.UU.), 128 F. $3 \mathrm{~d} 233$.

Snyder vs Phelps et al. (2011): Corte Suprema de EE.UU., 562 U.S. (slip opinion). Disponible en: <www.supremecourt.gov/opinions/10pdf/09-751.pdf> [fecha de consulta: 19 de mayo de 2011].

The Islamic Unity Convention vs. The Independent Broadcasting Authority (2002): Corte Constitucional de Sudáfrica, CCT36/01.

The Prosecutor vs. Jean-Paul Akayesu (1998): Tribunal Penal Internacional para Ruanda, ICTR-96-4-T.

Trial of the Major War Criminals before the International Military Tribunal (1946): Tribunal

Militar Internacional (Núremberg), Vol. XXII, Official Text in the English Language.

Virginia vs. Black (2003): Corte Suprema de EE.UU., 538 U.S. 343.

Wisconsin vs. Mitchell (1993): Corte Suprema de EE.UU., 508 U.S. 476. 


\section{NORMAS CITADAS}

\section{Normas Nacionales y Proyectos de Ley}

Código Penal, 12 de noviembre de 1874.

Decreto N ${ }^{\circ} 100$, Fija el Texto Refundido, Coordinado y Sistematizado de la Constitución Política de la República de Chile. Diario Oficial 22 de septiembre de 2005.

Ley N ${ }^{\circ}$ 16.643, Sobre Abusos de Publicidad. Diario Oficial 4 de septiembre de 1967.

Ley $\mathrm{N}^{\circ} 19.253$, Establece Normas sobre Protección, Fomento y Desarrollo de los Indígenas, y Crea la Corporación Nacional de Desarrollo Indígena. Diario Oficial 5 de octubre de 1993.

Ley $\mathrm{N}^{\circ} 19.733$, Sobre Libertades de Opinión e Información y Ejercicio del Periodismo. Diario Oficial 4 de junio de 2001.

Proyecto de Ley sobre Discriminación Racial y Étnica. Boletín 2142-17.

Proyecto de Ley que Establece Medidas contra la Discriminación. Boletín 3815-07.

\section{Normas Extranjeras y Tratados Internacionales}

Canadian Charter of Rights and Freedoms, 17 de abril de 1982.

Canadian Human Rights Act, Chapter H-6, consolidado de 2 de diciembre de 2009.

Code Pénal (Francia), consolidado de 1 de julio de 2010.

Código Penal (España), Ley Orgánica 10/1995, 23 de noviembre de 1995.

Constitución de la República de Hungría (versión en inglés), promulgada originalmente el año 1949 y ampliamente reformada el 23 de octubre de 1989. Disponible en: <http:// mkab.hu/index.php?id=constitution $>$ [fecha de consulta: 25 de octubre de 2010].

Constitución de los Estados Unidos de América, 21 de junio de 1788 (versión en español). Disponible en: <http://www.archives.gov/espanol/constitucion $. h t m l>$ [fecha de consulta: 25 de octubre de 2010].

Convención Americana sobre Derechos Humanos (Pacto de San José), ratificada por Chile el 10 de agosto de 1990.

Convención Internacional sobre la Eliminación de todas las Formas de Discriminación Racial, ratificada por Chile el 20 de octubre de 1971.

Convención para la Prevención y la Sanción del Delito de Genocidio, ratificada por Chile el 3 de junio de 1953.

Convenio Europeo para la Protección de los Derechos Humanos y de las Libertades Fundamentales, 4 de noviembre de 1950.

Criminal Code C-46 (Canadá), consolidado de 21 de enero de 2010.

Decisión Marco 2008/913/JAI, Relativa a la Lucha Contra Determinadas Formas y Manifestaciones de Racismo y Xenofobia Mediante el Derecho Penal (Consejo de la Unión Europea), 28 de noviembre de 2008.

Declaración de Principios sobre Libertad de Expresión, Comisión Interamericana de DD.HH., $108^{\circ}$ período ordinario de sesiones celebrado del 2 al 20 de octubre de 2000.

Human Rights Act (Reino Unido), 9 de noviembre de 1998. 
Ley Fundamental de la República Federal de Alemania (traducción al castellano), 23 de mayo de 1949. Disponible en: <http://constitucion.rediris.es/legis/legextr/ Constitucion Alemana.html> [fecha de consulta: 25 de octubre de 2010].

Loi Tendant à Réprimer Tout Acte Raciste, Antisémite ou Xénophobe, "Loi Gayssot" (Francia), Ley N 90-615, 13 julio de 1990.

Matthew Shepard and James Byrd, Jr. Hate Crimes Prevention Act (EE.UU.), 28 de octubre de 2009.

Pacto Internacional de Derechos Civiles y Políticos, ratificado por Chile el 10 de febrero de 1972.

Prohibition of Incitement to Hatred Act (República de Irlanda), 29 de noviembre de 1989. Racial and Religious Hatred Act (Inglaterra y Gales), 16 de febrero de 2006.

Violent Crime Control and Law Enforcement Act (EE.UU.), 25 de enero de 1994. 
